\title{
Caracterização do abacaxi e sua casca como alimento funcional: revisão narrativa
}

\author{
Characterization of pineapple and its peel as a functional food: narrative review \\ Caracterización de lapiña y sucáscara como alimento funcional: revisión narrativa
}

\author{
Nágila Iane Pacheco \\ ORCID: https://orcid.org/0000-0002-2836-1639 \\ Centro Universitário UniFacid/Wyden, Brasil \\ E-mail: nagilaiane@hotmail.com \\ Luiza Aragão Paiva Pires Ferreira Mendes \\ ORCID: https://orcid.org/0000-0002-4017-6102 \\ Centro Universitário UniFacid/Wyden, Brasil \\ E-mail: luizamendes0412@gmail.com \\ Gabriel de Sousa Carneiro \\ ORCID: https://orcid.org/0000-0002-0881-7870 \\ Faculdade Maurício de Nassau, Brasil \\ E-mail: gabrieldesousa2735@gmail.com \\ Danielle Costa Lopes \\ ORCID: https://orcid.org/0000-0002-7382-1323 \\ Universidade Federal do Piauí, Brasil \\ E-mail: dany197_@hotmail.com \\ Ivanira Vieira Loiola Coutinho \\ ORCID: https://orcid.org/0000-0003-1877-1885 \\ Centro Universitário UniFacid/Wyden, Brasil \\ E-mail: ivanirafarma@gmail.com \\ Ana Kaylany Alves Pinto da Silva \\ ORCID: https://orcid.org/0000-0002-3344-8771 \\ Centro Universitário UniFacid/Wyden, Brasil \\ Email: anakayllany.02@icloud.com \\ Karla Beatriz Rocha Rodrigues \\ ORCID: https://orcid.org/0000-0001-6156-1555 \\ Centro Universitário UniFacid/Wyden, Brasil \\ E-mail: karlabrrr2@gmail.com \\ Lyslly Rhanny Soares De Deus \\ ORCID: https://orcid.org/0000-0003-4367-5609 \\ Centro Universitário UniFacid/Wyden, Brasil \\ E-mail: lysllyrhanny@hotmail.com \\ Alciene Pacheco da Silva \\ ORCID: https://orcid.org/0000-0003-4117-2792 \\ Universidade Federal do Piauí, Brasil \\ E-mail: alcienepacheco@ufpi.edu.br \\ Thalita Yanomany Lima Leal de Sousa \\ ORCID: https://orcid.org/0000-0003-3069-582X \\ Centro Universitário UniFacid/Wyden, Brasil \\ E-mail: thalitayanomany@hotmail.com
}

\begin{abstract}
Resumo
Introdução: A palavra alimento funcional, pode ser descrita como qualquer matéria/ingrediente usada como alimento no auxílio da prevenção de doenças ou melhoria da qualidade de vida. O abacaxi é uma planta perene, pertencente à família Bromeliaceae, muito apreciado nas regiões produtoras e nos países importadores, devido suas características de aroma e sabor, mantendo equilíbrio entre o açúcar e acidez. A casca do abacaxi é um insumo não valorizado nas indústrias de alimentos, que pode auxiliar na dieta humana de forma complementar. Este estudo tem como objetivo divulgar a caracterização do abacaxi e sua casca apresentando suas propriedades por meio de uma revisão narrativa. Metodologia: Para o levantamento dos artigos científicos na literatura, realizou-se pesquisa através dos bancos de dados online da BVS, SCIELO, Science Direct, MEDLINE, LILACS e PMC, UFRGS, UFPA, SEBRAE, e Google School nos idiomas inglês, espanhol e português. Resultados e discussões: A composição química do abacaxi se diversifica sobretudo conforme a época do ano em que é gerada, sua diversidade e as condições atmosféricas, este apresenta valor energético, e alta composição de açúcar e valor nutritivo devido a presença de sais minerais (cálcio, fósforo, magnésio, potássio, sódio, cobre e iodo) e de vitaminas (C, A, B1, B2 e Niacina). Conclusão: A bromelina é uma enzima proteolítica encontrada no abacaxizeiro que mostram efeitos anti-inflamatórios, antitumoral, auxilia na digestão dos alimentos, anti-trombose, queimaduras e mucolítico.
\end{abstract}

Palavras-chave: Abacaxi; Alimento funcional; Bromelina; Ananas comosus. 


\begin{abstract}
Introduction: The word functional food can be described as any material/ingredient used as food to help prevent disease or improve quality of life. Pineapple is a perennial plant, belonging to the Bromeliaceae family, much appreciated in producing regions and in importing countries, due to its aroma and flavor characteristics, maintaining a balance between sugar and acidity. Pineapple peel is an input not valued in the food industries, which can help in the human diet in a complementary way. This study aims to disclose the characterization of pineapple and its peel, presenting its properties through a narrative review. Methodology: For the survey of scientific articles in the literature, a search was carried out through the online databases of the VHL, SCIELO, Science Direct, MEDLINE, LILACS and PMC, UFRGS, UFPA, SEBRAE, and Google School in English, Spanish and Portuguese. Portuguese. Results and discussions: The chemical composition of pineapple varies mainly according to the time of year in which it is generated, its diversity and the atmospheric conditions, it has energy value, and high composition of sugar and nutritional value due to the presence of mineral salts (calcium, phosphorus, magnesium, potassium, sodium, copper and iodine) and vitamins (C, A, B1, B2 and Niacin). Conclusion: Bromelain is a proteolytic enzyme found in pineapple that shows anti-inflammatory, antitumor, aids in food digestion, anti-thrombosis, burns and mucolytic effects.
\end{abstract}

Keywords: Pineapple; Functional food; Bromelain; Ananas comosus.

\title{
Resumen
}

Introducción: La palabra alimento funcional puede describirse como cualquier material/ingrediente utilizado como alimento para ayudar a prevenir enfermedades o mejorar la calidad de vida. La piña es una planta perenne, perteneciente a la familia de las Bromeliáceas, muy apreciada en las regiones productoras y en los países importadores, por sus características de aroma y sabor, manteniendo un equilibrio entre azúcar y acidez. La cáscara de piña es un insumo no valorado en las industrias alimentarias, que puede ayudar en la dieta humana de manera complementaria. Este estudio tiene como objetivo divulgar la caracterización de la piña y su cáscara, presentando sus propiedades a través de una revisión narrativa. Metodología: Para el levantamiento de artículos científicos en la literatura se realizó una búsqueda a través de las bases de datos en línea de la BVS, SCIELO, Science Direct, MEDLINE, LILACS y PMC, UFRGS, UFPA, SEBRAE y Google School en inglés, español y Portugués Portugués. Resultados y discusiones: La composición química de la piña varía principalmente según la época del año en que se genera, su diversidad y las condiciones atmosféricas, tiene valor energético, y alta composición de azúcares y valor nutritivo por la presencia de sales minerales. (calcio, fósforo, magnesio, potasio, sodio, cobre y yodo) y vitaminas (C, A, B1, B2 y Niacina). Conclusión: La bromelina es una enzima proteolítica que se encuentra en la piña que muestra efectos antiinflamatorios, antitumorales, ayuda en la digestión de alimentos, antitrombosis, quemaduras y efectos mucolíticos.

Palabras clave: Piña; Comida funcional; Bromelina; Ananas comosus.

\section{Introdução}

Neste início do século XXI, os alimentos funcionais são a nova tendência do grande mercado alimentício. A preocupação da população pela sua saúde e bem-estar, alterações na regulamentação dos alimentos e a ampla comprovação científica das relações presentes entre dieta e saúde, são os fatores-chave deste modismo (Casemiro, 2014). A expressão alimento funcional, é descrita como qualquer matéria/ingrediente aplicada no auxílio da prevenção de doenças ou melhoria da qualidade de vida. Estas s apresentam um efeito preciso sobre o bem-estar físico e psicológico da pessoa, consumindo-os na forma de alimentos ou bebidas, e não pílulas, cápsulas ou drágeas (Ikeda et al., 2010).

O mercado de alimentos funcionais permanece em ascensão no mundo inteiro. De acordo com uma pesquisa realizada pela Euromonitor, o Brasil é o $4^{\circ}$ colocado em consumo de alimentos saudáveis no ranking global, movimentando cerca de US\$ 35 bilhões por ano. Os dados obtidos através do Brasil Food Trends (2020) confirmam essa evolução ao revelar que o mercado de alimentação saudável vem experimentando um crescimento médio de 12,3\% ao ano. Este setor obteve grande acréscimo no segmento de bebidas e de alimentos saudáveis, devendo apresentar um aumento até 2021 (Sebrae, 2019).

Os alimentos que compreendem os nutrientes funcionais mais pesquisados são: a soja, as crucíferas, os brócolis, abacaxi, couve de bruxelas, repolho, o tomate, a linhaça, o alho, a cebola, o chá verde, as frutas cítricas, as uvas/vinho tinto, os peixes, os óleos de peixe, os cereais com aveia, os prebióticos e os probióticos. Estes alimentos possuem os componentes ativos que atuam sobre o organismo gerando os efeitos fisiológicos e metabólicos favoráveis para a saúde (Universidade Federal do Pará- UFPA, 2012). 
Dentre esses, o abacaxi destaca-se pelo valor energético, pela sua alta composição do açúcar e pela atividade proteolítica que auxiliam no processo de digestão dos alimentos, contendo como a principal fonte de extração de bromelina. No entanto, o teor de proteínas e gorduras é inferior a 0,5\% (Matsuura \& Rolim, 2002). A sua casca é um insumo, que embora não seja valorizado nas indústrias de alimentos, auxiliam na dieta humana de forma complementar.

O processamento dessa fruta apresenta como um dos impasses a quantidade de resíduos orgânicos gerados nas indústrias alimentícias. Estes resíduos vegetais que são as cascas, coroas e talos, são utilizados nas composições de chás e sucos, possibilitando uma fonte alternativa de nutrientes (Oliveira, 2014). Esses mesmos apresentam peso em torno de $30 \%$ a $40 \%$ em relação ao peso do fruto e empregues na alimentação humana, agrupando valor econômico e ambiental para as indústrias, além de melhorar a qualidade de vida por meio do valor nutricional advindos das fibras, vitaminas, minerais e compostos antioxidantes indispensáveis para o organismo (Sobrinho, 2014; Vieira, et al., 2017).

A polpa é composta por vitaminas, açúcares e fibras alimentares, porém contém baixa fonte de vitamina C. Logo, a casca contém em sua composição teor nutricional que reforça os minerais em cerca de 4,74\% e fibras alimentares em torno de $17,92 \%$, que apresentam ação antioxidante, auxiliam na digestão e atuam como anti-inflamatório. A mesma possui grande aceitação sensorial por parte dos consumidores devido os seus benefícios ao corpo humano (Neres et al., 2015). Desse modo, o abacaxi possui na sua polpa e na sua casca, grande valor nutricional, tornando-se um alimento de fácil disponibilidade e baixo custo. Com isso, este trabalho contém como objetivo divulgar a caracterização do abacaxi e sua casca apresentando suas propriedades por meio de uma revisão narrativa.

\section{Metodologia}

Para o levantamento dos artigos científicos na literatura, realizou-se através dos bancos de dados online: Biblioteca Virtual de Saúde (BVS), Scientific Electronic Library Online (SCIELO), Science Direct, PubMed Central (PMC), Universidade Federal do Rio Grande do Sul (UFRGS), Universidade Federal do Pará (UFPA), SEBRAE, e Google School. Retiraram-se como parâmetro de inclusão para o levantamento, os descritores em português: Abacaxi; Alimento Funcional; Bromelina; Ananas comosus, em inglês: Pineapple; Functional food; Bromelain; Ananas comosus e em espanhol, Piña; Comida funcional; Bromelina; Anana scomosus, combinados entre si pelos descritores booleanos "AND”.

Os critérios de inclusão definidos para a seleção dos artigos foram: os publicados em português, inglês e espanhol, que na íntegra retratassem a temática referente ao abacaxi e as cascas do abacaxi. Ademais, publicados e indexados nos referidos bancos de dados dos anos de 2000 a 2022, totalizou-se no total 107 artigos incluídos e 47 excluídos, que após a leitura não atenderam a finalidade da pesquisa. Analisaram-se os argumentos e ideias encontradas de acordo com a relevância do tema proposto na pesquisa e em seguida organizada e citadas (Quadro 1).

Realizou-se a análise e a síntese dos dados extraídos dos artigos de forma descritiva, possibilitando observar, contar, descrever e classificar os dados, com o intuito de reunir o conhecimento produzido sobre o tema explorado na revisão. Contendo em vista que os artigos selecionados como um potencial adequado para a contribuição da revisão da literatura do presente trabalho. 
Quadro 1: Artigos científicos listados dos bancos de dados.

\begin{tabular}{|c|c|c|}
\hline Título do artigo & Título do artigo & Título do artigo \\
\hline $\begin{array}{l}\text { Extração, atividade da bromelina e análise de alguns parâmetros químicos em } \\
\text { cultivares de abacaxi }\end{array}$ & Abílioet al., 2009 & SCIELO \\
\hline Qualidades físicas e químicas do abacaxi comercializado na CEAGESP São Paulo. & Bengozi, et al., 2007 & SCIELO \\
\hline Das Américas para o Mundo - origem, domesticação e dispersão do abacaxizeiro & Crestani, M. et al., 2010 & SCIELO \\
\hline Composição centesimal e de minerais em cascas de frutas. & Gondim, J. A. M. et al., 2005 & SCIELO \\
\hline Metabólitos secundários da família bromeliaceae & Manetti, L. et al., 2009 & SCIELO \\
\hline $\begin{array}{l}\text { Physical, chemical and microbiological characterization of deboned dry-curedham } \\
\text { with added lactulose. }\end{array}$ & Lima, Í. A. et al., 2017 & SCIELO \\
\hline $\begin{array}{l}\text { Avaliação da adição de suco de acerola em Suco de abacaxi visando à Produção de } \\
\text { um "blend" com Alto Teor de vitamina C. }\end{array}$ & $\begin{array}{l}\text { Matsuura, F. C. A. U., \& } \\
\text { Rolim, R. B. (2002). }\end{array}$ & SCIELO \\
\hline $\begin{array}{l}\text { Composição físico-química e aceitação sensorial da inflorescência de gengibre } \\
\text { orgânico (ZingiberofficinaleRoscoe). }\end{array}$ & Lucio, I. B et al., 2010 & SCIELO \\
\hline $\begin{array}{l}\text { Valor nutritivo do subproduto da indústria processadora de Abacaxi em dietas para } \\
\text { ovinos }\end{array}$ & Rogério, M.C.P. et al., 2004 & SCIELO \\
\hline $\begin{array}{l}\text { Valor nutritivo do resíduo da indústria processadora de abacaxi (AnanascomosusL.) } \\
\text { em dietas para ovinos. }\end{array}$ & Rogério, M. C. P. 2007 & SCIELO \\
\hline $\begin{array}{l}\text { Temperatura e tipo de preparo na conservação de produto minimamente processado } \\
\text { de abacaxi 'Pérola' }\end{array}$ & Sarzi, B. et al., 2002 & SCIELO \\
\hline Bromelain separation and purification processes from pineapple extract. & Abreu, D. C. A. (2019). & SCIELO \\
\hline $\begin{array}{l}\text { Bromelain and } \mathrm{N} \text {-acetyl cysteine inhibit the proliferation and survival of } \\
\text { gastrointestinal cancercells in vitro: the meaning of combination therapy. }\end{array}$ & Amini, A. et al., 2014 & PUBMED \\
\hline Health benefits of dietary fiber & Anderson, J. W. et al., 2009 & PUBMED \\
\hline $\begin{array}{l}\text { Antimetastatic effect of bromelain with or without its proteolytic and anticoagulant } \\
\text { activity. }\end{array}$ & Batkin, S. et al., 1988 & PUBMED \\
\hline American Gastroenterological Association technical review on constipation. & Bharucha, A. E. et al., 2013 & PUBMED \\
\hline $\begin{array}{l}\text { WW domains } 2 \text { and } 3 \text { of Rsp5p play overlapping roles in bindingtothe LPKY } \\
\text { motifof Spt } 23 p \text { and Mga2p }\end{array}$ & Bhattacharya, S. et al., 2008 & PUBMED \\
\hline $\begin{array}{l}\text { Enhancement of anti-inflammatory activity of bromelain by its encapsulation in } \\
\text { katira gum nanoparticles. }\end{array}$ & Bernela, M. et al., 2016 & PUBMED \\
\hline $\begin{array}{l}\text { Bromelain inhibits COX-2 expression by blocking the activation of MAPK } \\
\text { regulated NF-kappa B against skin tumor-initiation triggering mitochondrial death } \\
\text { pathway. }\end{array}$ & Bhui, K. et al., 2009 & PUBMED \\
\hline $\begin{array}{l}\text { Bromelain inhibits nuclear factor kappa-B translocation, driving human epidermoid } \\
\text { carcinoma A431 and melanoma A375 cells through } \mathrm{G}(2) / \mathrm{M} \text { arrest to apoptosis. }\end{array}$ & Bhui, K. et al., 2012 & PUBMED \\
\hline $\begin{array}{l}\text { Enzymatic debridement for the treatment of severely burned upper extremities - } \\
\text { early single center experiences }\end{array}$ & Cordts, T. et al., 2016 & PUBMED \\
\hline $\begin{array}{l}\text { Proteolytic Inhibition of Salmonella enterica Serovar Typhimurium-Induced } \\
\text { Activation of the Mitogen-Activated Protein Kinases ERK and JNK in Cultured } \\
\text { Human Intestinal Cells }\end{array}$ & Mynott, T. L. et al., 2002 & PUBMED \\
\hline
\end{tabular}


Herbal anti-inflammatory agents for skin disease.

Herbal medicines for the treatment of rhinosinusitis: a systematic review.

Bromelain treatment alters leukocyte expression of cell surface molecules involved in cellular adhesion and activation.

Proteinase activity and stabilityof natural bromelain preparations.

Treatment with oral bromelain decreases colonic inflammation in the IL-10deficient murine model of inflammatory bowel disease.

Natural treatment of chronic rhinosinusitis.

Pharmacological approaches to discovery and development of new mucolytic agents.

Enzymatic necrolysis of acute deep burns--report of preliminary results with 22 patients.

Efficacy of enzymatic debridement of deeply burned hands.

Functional foods: Latin American perspectives.

Nutritional support for wound healing.

Bromelain exerts anti-inflammatory effects in an ovalbumin-induced murine model

of allergic airway disease.

Proteolytic Inhibition of Salmonella enterica Serovar Typhimurium-Induced Activation of the Mitogen-Activated Protein Kinases ERK and JNK in Cultured Human Intestinal Cells

\begin{tabular}{|c|c|}
\hline Graf J. (2000). & PUBMED \\
\hline Guo, R. et al., 2006 & PUBMED \\
\hline Hale, L. P. et al., 2002 & PUBMED \\
\hline Hale, L. P. et al., 2005 & PUBMED \\
\hline $\begin{array}{c}\text { Hale, L. P. et al., 2005 } \\
\text { Helms, S. (2006). }\end{array}$ & PUBMED \\
\hline $\begin{array}{c}\text { King, M., \& Rubin, B. K. } \\
\text { (2002). }\end{array}$ & PUBMED \\
\hline
\end{tabular}

Properties and Therapeutic Application of Bromelain: A Review

Anticancer property of bromelain with therapeutic potential in malignant peritoneal mesothelioma

Bromelain: from production to commercialisation

Functional food concept and its application to prebiotics

Selectivity of a bromelain based enzymatic debridement agent: a porcine study.

Efficacy and tolerability of bromelain in patients with chronic rhinosinusitis--a pilotstudy.

Food and agriculture organization of the united nations - FAO.

Resolução no 54, de 12 de novembro de 2012 - Regulamento técnico sobre informação nutricional complementar.

O Que São Alimentos Funcionais?

Institutional barriers for food innovation : a study of the Brazilian functional food industry

O cultivo e o mercado do abacaxi.

Expression, purification, and characterization of a recombinant stem bromelain.

Extraction of bromelain from pineapple core and purification by RME and precipitation methods

An integrated approach for pineapple waste valorisation. Bioethanol production and bromelain extraction from pineapple residues

Optimization of bromelain isolation from pineapple by products by polysaccharide complex formation.

\begin{tabular}{|c|c|}
\hline Mynott, T. L. et al., 2002 & PUBMED \\
\hline Pavan, R. et al., 2012 & PUBMED \\
\hline Pillai, K. et al., 2013 & PUBMED \\
\hline Ramli, A. N. et al., 2017 & PUBMED \\
\hline Roberfroid, M. (2002) & PUBMED \\
\hline Rosenberg, L. et al., 2012 & PUBMED \\
\hline Büttner, L. et al. 2013 & PUBMED \\
\hline FOA, 2013 & FOA \\
\hline Brasil. (2012). & Brasil \\
\hline UFPA (2012) & UFPA \\
\hline Oliveira, G. R. et al., 2014 & UFRGS \\
\hline Sebrae (2016) & SEBRAE \\
\hline Amid, A. et al., 2011 & Science Direct \\
\hline $\begin{array}{c}\text { Chaurasiya, R.S.; Hebbar, } \\
\text { H.U. (2013). }\end{array}$ & Science Direct \\
\hline $\begin{array}{l}\text { Gil, L. S., \&Maupoey, P. F. } \\
\text { (2018). }\end{array}$ & Science Direct \\
\hline Campos, D. A. et al., 2019 & Science Direct \\
\hline
\end{tabular}


The first survey of gap between the actualla belling and efficacy information of functional substances in food underthe regulatory processes in Japan.

Science Direct

A review of solar drying technologies.

Total phenolics, flavonoids and antioxidant activity of tropical fruit pineapple.

Isotermas de dessorção de resíduos de abacaxi.

Bromelaína. In: Utilidade de Bromelaína e N-Acetilcisteína no Tratamento da Disseminação Peritoneal de Malignidades Produtoras de Mucina Gastrointestinal

Alimentos funcionais em angiologia e cirurgia vascular

Bromeliaceae: profile of an adaptive radiation.

Fração P1G10 do látex de Vasconcelleacundinamarcensis: atividade antitrombótica in vivo e anticoagulante/antiagregante plaquetária in vitro.

Produção de suco de abacaxi obtido a partir dos resíduos da indústria conserveira.

Caracterização físico-química, enzimática e aceitação sensorial de três cultivares de abacaxi.

Produção científica sobre alimentos funcionais: uma análise das publicações brasileiras entre 2007 e 2013.

Análise de viabilidade econômica de um processo de extração de purificação da bromelina do abacaxi.

Development of light pineapple jam with propolis.

Comparação dos parâmetros físico-químicos e químicos de pós alimentícios obtidos de resíduos de abacaxi.

Extração, purificação parcial e comparação de duas técnicas de precipitação de enzimas proteolíticas do abacaxizeiro.

A new procedure based on column chromatography to purify bromelain by ion exchange plus gel filtration chromatographies

Educação em saúde sobre atenção alimentar: uma estratégia de intervenção em enfermagem aos portadores de diabetes mellitus.

Consumo de alimentos funcionais em unidades de alimentação e nutrição de Santa Maria/RS.

Desenvolvimento e produtividade do abacaxizeiro 'smoothcayenne' em função de adubação nitrogenada e tipos de mudas no norte fluminense.

Sanjairaj, V.etal, 2012

Sanjairaj, V. et al., $2012 \quad$ Science Direct

Hossain, M.A. (2011)

Scienc Direct

Alexandre, H. V. et al., $2015 \quad$ Google School

Amini, A. et al., 2016

Google School

ANJO, D. L. C. (2004).

Google School

Benzing, D.H. et al., 2000

Google School

Bilheiro, R.P. (2012).

Google School

Borges, C. et al., 2005

Google School

Brito, C. A. K. et al., 2008

Google School

Casemiro, I. P., \& Ramos, P. (2014)

Google School

Cesar, A.C.W. (2005)

Google School

Chaves, A. C. C. et al., 2015

Google School

Costa, J. M. C. et al., 2007

Google School

Costa, H. B. et al., 2008

Google School

Costa, H.B., et al., 2014

Google School

Costa, J. R. G., et al., 2016

Google School

Colpo, E. et al., 2016

Google School

Faria, D. C. (2008).

Google School

Caracterização e purificação da enzima bromelina em sistema de duas fases aquosas PEG/Fosfato.

Ferreira, J. F. (2007).

Google School

Purificação da enzima bromelina presente no curauá (Ananas erectifolius L.B.

SMITH) variedade roxa, por sistema bifásico aquoso peg 4000/fosfato de potássio.

Ferreira, J.F. et al., 2011

Google School

Estudos bioquímicos da enzima bromelina do Ananas comosus (abacaxi)

Abacaxi: produção, mercado e subprodutos

Alimentos Funcionais: Uma Alternativa Nutricional?

Alimentos funcionais - aspectos gerais.

Considerações sobre tendências e oportunidades dos alimentos funcionais

França, A. S. et al., 2009

França, A. S. et al., 2009

Google School

Granada, G. et al., 2005

Google School

Góes, L.B. (2008).

Google School

Arabbi, P. R. (2001).

Google School

Ikeda, A. A. et al., 2010

Google School

Agroindustrial use of waste from minimum processed pineapple 'pérola'

Lima, P. C. C. et al., 2017

Google School 
Avaliação da sinérese em geléia de abacaxi por meio de análise uni e multivariada. Efeito do consumo de Kefir sobre parâmetros bioquímicos relacionados ao Diabetes Mellitus: uma revisão de literatura

Avaliação sensorial de bolo com resíduo de casca de abacaxi para suplementação do teor de fibras.

Obtenção, caracterização e aplicação de farinha das cascas de abacaxi e de manga.

Alimentos Funcionais e Nutracêuticos: Definições, Legislação e Benefícios à Saúde

Obtenção, caracterização e aplicação de farinha de resíduos de frutas em cookies.

Cultivo do abacaxi em Rondônia

Desenvolvimento e análise sensorial da geleia de polpa e casca de abacaxi com gengibre.

Iogurte com polpa e farinha da casca do abacaxi.

Characteristic properties of crude pineapple waste extract for bromelain purification by membrane processing.

Controle do fungo penducular do abacaxi pérola.

Os Avanços do Uso da Bromelina nos Efeitos da Cicatrização da Pele e AntiInflamatório. Revista Acadêmica Online.

Os avanços do uso da bromelina nas áreas da alimentação e saúde

Estudo da secagem de casca de abacaxi visando desenvolvimento de chá a partir do produto seco.

Abacaxi: o produtor pergunta, a Embrapa responde.

Alimentos funcionais.

Aproveitamento da casca de abacaxi na confecção de geleia.

Avaliação da composição centesimal de casca de abacaxi (1-4).

Caracterização físico-química e purificação da bromelina no Ananascomosus (L.)

Merrill (ABACAXI-BROMELIACEAE).

Obtenção e caracterização de bromelina a partir de diferentes partes do abacaxizeiro Ananascomosus.

Effect of $\mathrm{pH}$ and Temperature on the Activity of Enzymatic Extracts from Pineapple Peel.

Determination of sugar content in pineapple waste variety N36.

Propriedades Nutricionais e Funcionais de resíduos de abacaxi, acerola e cajá oriundos da indústria produtora de polpas.

Alimentos funcionais no manejo do Diabetes Melitus tipo 2: uma abordagem bibliográfica.

Sensibilização de adultos hipertensos sobre a importância do consumo de alimentos funcionais em uma unidade básica de saúde de piripiri-pi.

Conceitos em Fitoterapia: Uma revisão da literatura. Abacaxi/Bromelina.

A ingestão de alimentos funcionais e sua contribuição para a diminuição da incidência de doenças.

Aceitabilidade e características físico-quimicas de geleia mista de casca de abacaxi e polpa de pêssego.

Avaliação e quantificação da vitamina c no blend de abacaxi com acerola.

\begin{tabular}{|c|c|}
\hline Licodiedoff, S. et al., 2010 & Google School \\
\hline Marques, C. G. et al., 2019 & Google School \\
\hline Martin, J. G. P. et al., 2012 & Google School \\
\hline Mendes, B. A. B. (2013). & Google School \\
\hline $\begin{array}{l}\text { Moraes, F.P.; Colla, L.M. } \\
\text { (2006) }\end{array}$ & Google School \\
\hline Moreno, J. S. (2016) & Google School \\
\hline Nascente, A. S. et al., 2005 & Google School \\
\hline $\begin{array}{l}\text { Nascimento, A.L.; Rabelo, } \\
\text { D.M. (2018). }\end{array}$ & Google School \\
\hline Neres, J. P. G. et al., 2015 & Google School \\
\hline Nor, M.Z.M. et al., 2015 & Google School \\
\hline Ribeiro, W. S. et al., 2011 & Google School \\
\hline Ribeiro, B. J. S. et al., 2020 & Google School \\
\hline Oliveira, L.F. (2001). & Google School \\
\hline Oliveira, A. S. B. (2014). & Google School \\
\hline Sanches, N. F. (2013). & Google School \\
\hline Salgado, J. (2017). & Google School \\
\hline Santini, A. T. et al., 2013 & Google School \\
\hline Santos, A. R. R. et al., 2010 & Google School \\
\hline Silva, R. A. (2008). & Google School \\
\hline Silva, I. D. (2013) & Google School \\
\hline Silvestre, M. et al., 2012 & Google School \\
\hline Siti Rocha, A.M. et al., 2013 & Google School \\
\hline Sobrinho, I. S. B. (2014). & Google School \\
\hline Sousa, F. C. A. et al., 2018 & Google School \\
\hline $\begin{array}{l}\text { Sousa, A. A. S., \& Moura } \\
\text { Fé, L. A. D. M. (2017). }\end{array}$ & Google School \\
\hline Teixeira, P. J.B. (2013). & Google School \\
\hline Vidal, A. M. et al., 2012 & Google School \\
\hline Vieira, E. C. S. et al., 2017 & Google School \\
\hline $\begin{array}{l}\text { Pecosch, A. F., Tizon, A. C. } \\
\text { (2011). }\end{array}$ & Google School \\
\hline
\end{tabular}


Propriedades termodinâmicas de adsorção de água e cinética de secagem de subprodutos da industrialização de abacaxi (ananás comosus l.) - casca e cilindro central.

Fonte: Pacheco (2022).

\section{Desenvolvimento}

\subsection{Desenvolvimentos de alimentos funcionais: contexto e suas perspectivas.}

Por volta de 1980, no Japão, surgiu o termo alimento funcional criado pelo governo da época que obtinha a proposta de estudar as funções nutricionais e os efeitos metabólicos e fisiológicos no organismo (Costa, 2016). Os referidos possuem componentes capazes de diminuir o risco de doenças e auxiliar na proteção de doenças, como as cardiovasculares, câncer, infecções intestinais, obesidade e diabetes tipo 2 (Colpo, 2016).

Os alimentos funcionais são encarados como promotores de saúde por estarem relacionados à diminuição dos riscos de doenças crônicas e por serem encontrados em alimentos naturais ou preparados que apresentam substâncias funcionais (Moraes, 2006). Estes previnem seu aparecimento e ajudam o organismo no combate de forma eficaz. Não devem ser aplicados como remédios, mas como englobados numa dieta que são consumidas cotidianamente, em sua forma original, para o fortalecimento do organismo (Vidal et al., 2012).

Na Resolução 18 do Conselho Universitário (RDC) nº 18 (Seção 2.1) da Administração Nacional de Supervisão Sanitária (ANVISA), em 30 de abril de 1999, encontrou-se a definição de alegação funcional de alimento: “está relacionada ao papel de nutrientes ou não nutrientes com efeitos metabólicos ou fisiológicos no crescimento, desenvolvimento, manutenção e outras funções normais dos organismos humanos" (Nascimento, 2018). De acordo com Góes (2008), os alimentos funcionais estão separados em quatro categorias:

- Convencionais: apresentam benefícios para a saúde quando comparados a outros alimentos similares. Exemplo: hortaliças.

•Processados: apresentam algum tipo de modificação. Exemplo: alimentos que apresentam teor de gordura reduzido ou alimentos engrandecidos com antioxidantes;

-Ingredientes: exclusivamente acrescentados aos alimentos. Exemplo: fibras e organismos probióticos;

-Produzido de novos alimentos: através da biotecnologia ou por métodos diferenciados. Exemplo: enriquecimento de ovos com ácido graxo poli-insaturado ômega- 3.

Além da nutrição adequada, esses afetam beneficamente em uma ou mais funções-alvo do corpo, considerando-os funcionais, ao serem relacionados com o bem-estar, à saúde e a redução do risco de enfermidade (Roberfroid, 2002). Essas é um tipo de alimento que combina produtos comestíveis altamente flexíveis com moléculas biologicamente ativas, utiliza-os como estratégia para corrigir rotineiramente distúrbios metabólicos (Moraes, 2006). Apresenta-se a seguir algumas características desses (Roberfroid, 2002):

a) Necessário serem alimentos convencionais que são usados na dieta normal/comum;

b) Devem apresentar compostos por componentes naturais, com elevada concentração ou presentes em alimentos que geralmente não os suprimem.

c) É necessário apresentar efeitos positivos além do valor básico nutritivo, que podem aumentar o bem-estar e a saúde e/ou reduzir o risco de ocorrência de doenças, promovendo benefícios à saúde além de aumentar a qualidade de vida, incluindo os desempenhos físico, psicológico e comportamental;

d) Necessário o embasamento cientifico na alegação da propriedade funcional;

e) Pode-se constituir em um alimento natural ou um alimento no qual um componente tenha sido retirado; 
g) Pode ser um alimento que tenha sido modificado e que em sua natureza apresente um ou mais componentes;

h) Pode ser um alimento no qual tenha sido modificado a bioatividade de um ou mais componentes.

No entanto, deve-se enfatizar que esses alimentos não são aplicados para curar doenças, mas para ajudar o corpo a resistir a certas enfermidades ou impedir que apareçam. Portanto, não devem ser usadas como drogas, mas como adição à dieta diária para ajudar o corpo a funcionar normalmente, corroborando para conter mais energia e disposição ao dia, melhorando a qualidade de vida (Vidal et al., 2012).

Para que a finalidade deste alimento seja eficaz, é fundamental que o seu uso seja regular, tendo como indispensáveis fontes as frutas, verduras, cereais integrais, carne, leite de soja e alimentos ricos em ômega 3. Certos componentes químicos que contribuem para a funcionalidade são: carotenóides, flavonóides, ácidos graxos como ômega-3, prebióticos (frutooligossacarídeos e inulina), probióticos, fibras entre outros (Sousa, 2018; Marques, 2019).

Os ingredientes e alimentos funcionais são classificados quanto à origem: animal ou vegetal, ou serventia operando em seis pontos do organismo: no sistema cardiovascular; no sistema gastrointestinal; no metabolismo de substratos; no crescimento, no desenvolvimento e diferenciação celular; no comportamento das funções fisiológicas e como antioxidantes (Moraes, 2006).

Vários pesquisadores recomendaram definições, porém a mais aceita é a de Lajolo (2002), em que retrata o alimento funcional como um alimento similar em aparência ao alimento convencional, usada como parte da dieta habitual, capaz de fornecer efeitos metabólicos ou fisiológicos essenciais na preservação de uma boa disposição física e mental, contendo potencial em auxiliar na redução do risco de doenças crônico-degenerativas e contendo finalidades nutricionais básicas.

No presente, as diretrizes oficiais da Agência de Defesa do Consumidor apontam que as alegações de saúde devem ser investigadas através de evidências científicas. No momento que os consumidores acidentalmente consomem múltiplos alimentos com alegações de função (FFC) compondo o mesmo componente, mas rotulados com funções distintas, esses são capazes de experienciar eventos adversos, desagradáveis causados pela ingestão abundante, como diarreia com dextrina (Tanemura et al., 2020).

Apesar da procura da população por uma alimentação saudável e funcional, o sabor do alimento implica no consumo e na compra do mesmo, ou seja, o alimento deve ser gostoso e prazeroso. Cada pessoa contém uma necessidade diferente sobre um determinado ingrediente para o consumido e procuram nestes o auxílio para uma melhor saúde, bem-estar e energia. Os consumidores afetados ou não por algum problema de saúde, são classificados de acordo com suas motivações de consumo como mostra a Figura 1 a seguir (Ikeda et al., 2010): 
Figura 1 - Principais motivações de compra de alimentos funcionais.

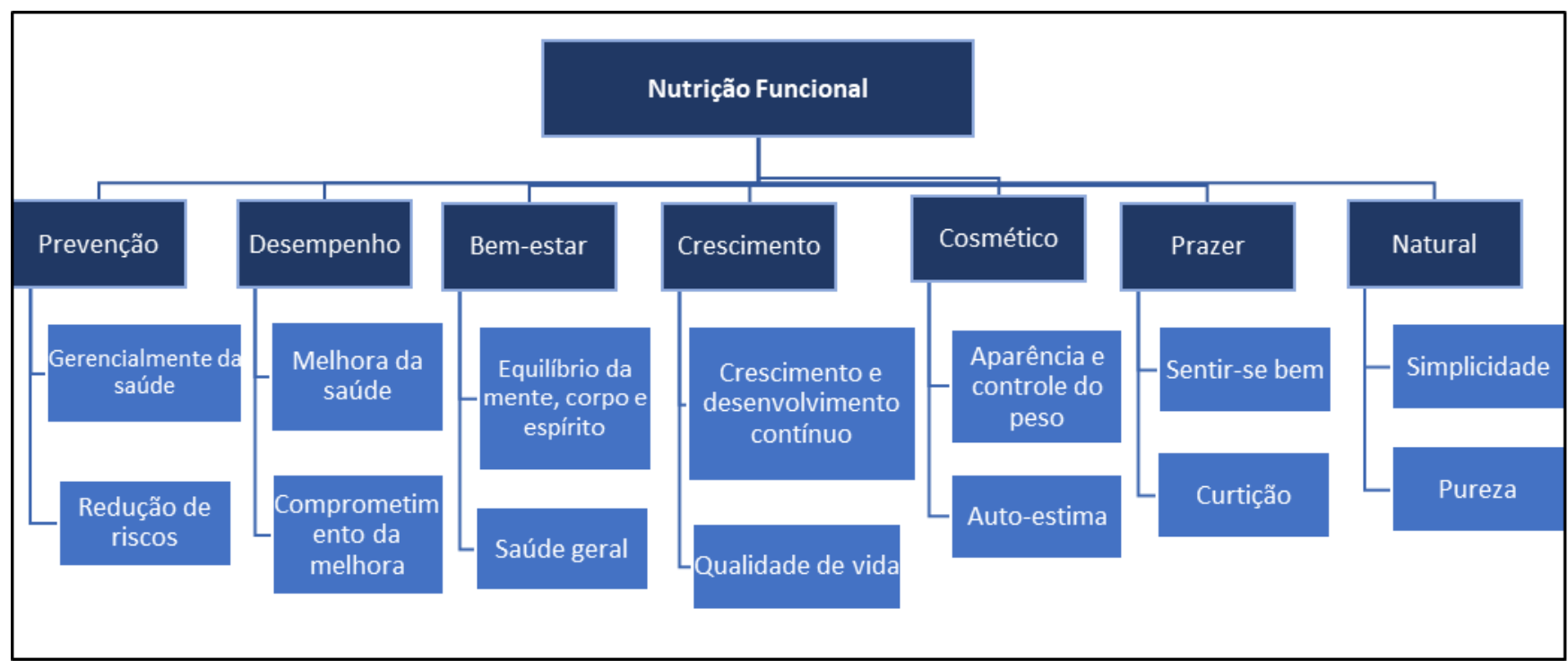

Fonte: Salgado (2017).

O modo como as pessoas se alimentam está diretamente ligado a fatores como circunstância momentânea, hábitos e situação social. Essas condições impulsionam um incentivo positivo ou negativo que induz em seu consumo habitual (Sousa, 2017). Sousa (2017) declara que a população mundial está buscando adotar uma alimentação mais saudável, atrás dos benefícios que conseguem alcançar por meio da alimentação, que apresentam em sua composição ingredientes que são indispensáveis para o bom andamento do organismo, por isso a essa é visada por muitos usuários com o propósito de possuir a expectativa de vida ampliada. Entretanto, apenas o consumo diário de alimentos funcionais não é o suficiente para tornar-se saudável, sendo este já citado, parte significativa para uma dieta sustentável e saudável (Oliveira et al., 2014).

\subsection{Abacaxi: propriedades agronômicas e terapêuticas.}

O abacaxi ou ananás, denominação pelos quais os mesmos são conhecidos tanto a planta como o fruto. Planta perene, pertencente à família Bromeliaceae os frutos categorizados como não climatéricos, apresentando em torno de 2.700 espécies, distribuídas em 56 gêneros. O fruto é constituído de 100 a 200 frutilhos, inseridos sobre uma haste central em disposição espiralada e intimamente unidos entre si. No ápice há um tufo de folhas, também conhecido como coroa (Granada, 2005; Benzinget al., 2000). A forma do fruto é cilíndrica ou cônica e sua massa varia de 1 a 3 kg (Viganó, 2012).

A palavra abacaxi em português é oriunda do tupi-guarani ibacaxi, composta de ibá (fruta) e caxicati (cheirosa), já a palavra ananás, é outro nome para abacaxi, proveniente também do tupi-guarani nanã (Viganó, 2012). O abacaxi é originário da América do Sul, descrita por outros autores como uma espécie de origem no Brasil. Apesar desta divisão da origem, reitera que esta fruta é plantada em qualquer região quente do mundo, conhecido por ananás, como é chamado nos países de língua espanhola (Nascente, 2005). Os abacaxis que são cultivados no Brasil são o Smooth Cayenne e Pérola, mas existe também o Perolena, Jupi, entre outras espécies em menor proporção. Esta planta exige boa luminosidade, com necessidade de 6 a 8 horas de luz solar por dia (Crestanil, 2010). Além disso, o sabor e aroma estão associados a inúmeros integrantes que a compõem, em destaque estão à sacarose, os ácidos cítrico e o málico (Licodiedoff et al., 2010).

O abacaxizeiro é uma planta monocotiledônea, herbácea. Encontradas nas regiões tropicais e subtropicais da América, a maioria das espécies de Broméliaceae existe em condições naturais (Silva, 2008). Devido aos benefícios econômicos e sociais proporcionados por essa atividade e às qualidades sensoriais de seus frutos, cresce em todos os países tropicais. No Brasil é cultivado em quase todos os estados, principalmente no mercado doméstico de frutas frescas (Faria, 2008; Brito et al., 
2008). Considerado uma das mais cultivadas pelo território brasileiro, o terceiro maior produtor mundial de abacaxi em 2012 e é considerada uma das frutas tropicais mais relevantes do mundo, com grande demanda no mercado de fruteiras (FAO, 2013).

A Ananascomosus é de clima tropical, apresenta crescimento ótimo e melhor qualidade de frutos na faixa de temperatura de 22 a $32^{\circ} \mathrm{C}$ e chuvas de 1200 a $1500 \mathrm{~mm}$ anuais (Nascenteet al., 2005). O abacaxi apresenta valor energético, e alta composição de açúcar e teores nutricionais devido à presença de sais minerais (cálcio, fósforo, magnésio, potássio, sódio, cobre e iodo) e de vitaminas (C, A, B1, B2 e Niacina) (Granada, 2005).

A qualidade do dessa é determinada a partir de suas características físicas: externas, que se refere ao tamanho, à casca e a forma do fruto, e a interna, que é comprovada por um conjunto de componentes físico-químicos da polpa, que são responsáveis pelo aroma, valor nutritivo e sabor. $\mathrm{O}$ aspecto de qualidade do fruto está agregado ao grau de maturação, a nutrição mineral e aos fatores climáticos (Bengoziet al., 2007). Durante a produção do abacaxi as frutas são classificadas entre seus defeitos graves e leves, e depois separadas. Os defeitos graves são (Hortibrasil, 2010):

- Lesões do fruto de origem mecânica, patológica ou entomológica; Decomposição/ Putrefação microbiológica;

- Frutos sem a presença da coroa;

- Alterações da cor natural da epiderme por excesso de radiação solar;

- Frutos que não alcançaram o Brix mínimo de $12^{\circ}$;

- Frutos que entraram no processo de envelhecimento, com coloração amarela completa, polpa límpida, odor muito forte, sem solidez e exsudado líquido;

- Obscuridade da polpa, de origem fisiológica;

- Polpa escurecida por efeito de geada;

- Conformação anormal da coroa e o topo do fruto que se apresentam de forma achatadas.

O abacaxi é muito apreciado nas regiões produtoras e nos países importadores, devido suas características de aroma e sabor, sendo um bom equilíbrio entre açúcar e acidez, apresentando em sua polpa a cor branca, amarela ou laranjaavermelhada. O seu peso depende de sua variedade, podendo ser encontrado entre 1 a 2,5 quilos. No caule, talo, raízes e folhas do abacaxizeiro de todas as suas espécies, encontram-se a bromelina um produto nobre da família Bromeliaceae (SEBRAE, 2016). Este fruto é consumido ao natural, ou na forma de sorvetes, doces, picolés, refrescos e sucos caseiros. Consumidos em enlatado, em calda, cristalizado, em forma de passa e picles e empregado na elaboração de cremes, balas, bolos, xarope, licor, vinho, vinagre e aguardente, além de serem aplicados como matéria-prima para a ração animal e extração de álcool, pela aplicação dos resíduos da industrialização (Crestanil, 2010; Alexandre et al., 2014).

Esse é abundante em nutrientes, e sua composição química pode sofrer alterações, consecutivos da espécie em que é cultivada, desde a fase de maturação, do período do plantio e colheita. O valor nutricional do mesmo está ligado ao teor de vitaminas, minerais e açúcares solúveis. O teor de sólidos solúveis, presente nos frutos maduros é entre $13^{\circ}$ Brix a $15^{\circ}$ Brix (Sanches, 2013). Ademais, possui excedência na quantidade de carboidratos, se amadurecido na planta, e elevada taxa de sais minerais, como o fósforo, magnésio, potássio, sódio, cobre, cálcio, iodo e vitaminas (A, B1, B2 e C) (Sobrinho, 2014; Crestani et al., 2010).

O abacaxizeiro é uma planta monocotiledônea, herbácea e perene, que contém grandes concentrações de Bromelina, e que está agregada ao tratamento de distúrbios digestivos e à hidrólise de proteínas, favorecendo assim a digestão (CHAVES, 2015). Esta enzima é também muito empregada na produção de medicamentos. Ela é diurética, depurativa e por ter ação antiinflamatória é utilizada no tratamento de hematomas, como solvente de mucosidades no sistema respiratório e contusões (Sobrinho, 2014). As espécies da família Bromeliaceae contêm um enorme potencial de aquisição de biocompostos, como enzimas de ação proteolítica e de metabólitos secundários com atividades antioxidantes, que são de interesse para a indústria 
farmacêutica e alimentar. A demanda por esses produtos está crescendo e de acordo com os seguintes princípios, é a tendência de substituir substâncias sintéticas por compostos de origem vegetal, alinhada com os princípios de sustentabilidade (Silva, 2013).

Estes constituintes ajudam na formação óssea do adolescente e auxiliam na prevenção da arteriosclerose, artrite e infecções na garganta. Em cada $100 \mathrm{~g}$ de polpa fresca de abacaxi contém aproximadamente 50 quilocalorias, $89 \%$ de água, $0,3 \%$ de proteína, $0,5 \%$ de lipídios, $5,8 \%$ de glicídios, $3,2 \%$ de celulose e $0,3 \%$ de sais, apresentando quantidade considerável de potássio, ferro, cálcio, manganês e magnésio (Sobrinho, 2014; Crestani et al., 2010). Demonstrado no Quadro 2 a seguir:

Quadro 2 - Composição química da polpa do abacaxi in natura.

\begin{tabular}{|l|c|}
\hline \multicolumn{1}{|c|}{ Componente } & $\begin{array}{c}\text { Quantidade (por 100 } \\
\text { gramas) }\end{array}$ \\
\hline Energia & $49 \mathrm{kcal}$ \\
\hline Umidade & $87,0 \mathrm{~g}$ \\
\hline Carboidrato Total & $11,6 \mathrm{~g}$ \\
\hline Proteína & $0,68 \mathrm{~g}$ \\
\hline Lipídios & $0,33 \mathrm{~g}$ \\
\hline Fibra alimentar & $1,12 \mathrm{~g}$ \\
\hline Colesterol & $0,00 \mathrm{mg}$ \\
\hline Cinzas & $0,36 \mathrm{~g}$ \\
\hline Cálcio & $18,4 \mathrm{mg}$ \\
\hline Ferro & $0,47 \mathrm{mg}$ \\
\hline Sódio & $2,84 \mathrm{mg}$ \\
\hline Magnésio & $16,6 \mathrm{mg}$ \\
\hline Fósforo & $10,5 \mathrm{mg}$ \\
\hline Potássio & $137 \mathrm{mg}$ \\
\hline Zinco & $0,15 \mathrm{mg}$ \\
\hline Cobre & $0,12 \mathrm{mg}$ \\
\hline Tiamina & $0,17 \mathrm{mg}$ \\
\hline Riboflavina & $0,02 \mathrm{mg}$ \\
\hline Niacina & $0,00 \mathrm{mg}$ \\
\hline Vitamina C & $33,1 \mathrm{mg}$ \\
\hline
\end{tabular}

Fonte: TBCA (2020).

A composição química do abacaxi se diversifica, sobretudo conforme a época do ano em que é gerada, sua diversidade e as condições atmosféricas. De acordo Granada (2005), seu valor nutricional depende, sobretudo, dos sólidos solúveis, das vitaminas e minerais existentes. Para Hossain e Rahman (2011), o abacaxi dispõe de um alto valor nutritivo, sua bioatividade funcional é especificada pela presença de compostos fenólicos que possibilitam uma boa ação antioxidante, além disso é fonte de vitaminas A, C e do complexo B, cálcio, fósforo e ferro.

Conforme Sarzi et al., (2002), identificou os dados aproximados no momento em que determinaram o rendimento de polpa minimamente processado, na proporção relacionada a cada porção, contendo no cilindro central 6,3\%, na polpa $60 \%$ e na casca $33,7 \%$. O quadro 3, a seguir, compreende os resultados da composição centesimal pertencentes às partes que integram este fruto. Os teores de umidade responderam substancialmente, do qual é seguida pelo miolo, polpa e casca. No caso da casca 
apresenta teor de umidade acima do valor identificado pelo autor que é 78,13\%, enquanto os dados relativos da umidade da polpa são similares (Gondim et al., 2005).

Quadro 3: Composição centesimal das partes do Abacaxi 'Pérola'.

\begin{tabular}{|c|c|c|c|c|c|c|c|}
\hline \multirow{2}{*}{$\begin{array}{l}\text { Produtos } \\
\text { (Abacaxi) }\end{array}$} & \multicolumn{6}{|c|}{ Composição centesimal (g.100g-1) } & \multirow{2}{*}{$\begin{array}{l}\text { Calorias } \\
\text { (Kcal. 100g-1) }\end{array}$} \\
\hline & Umidade & $\begin{array}{c}\text { Fração de } \\
\text { Cinzas }\end{array}$ & Proteína Bruta & Extrato Etéreo & Fibra Bruta & Carboidratos & \\
\hline Polpa & $\begin{array}{lll}85,43 & \text { c } & \pm \\
0,51 * & & \end{array}$ & $0,32 \mathrm{~b} \pm 0,01 *$ & $0,64 \mathrm{~b} \pm 0,04^{*}$ & $0,26 \mathrm{ab} \pm 0,006^{*}$ & $0,81 \mathrm{~b} \pm 0,02 *$ & $\begin{array}{lll}12,46 & \text { a } & \pm \\
0,50 * & & \\
\end{array}$ & $55,35 \mathrm{a} \pm 2,11^{*}$ \\
\hline Casca & $\begin{array}{lll}85,31 & \mathrm{c} & \pm \\
0,59 * & & \end{array}$ & $0,54 \mathrm{a} \pm 0,03^{*}$ & $0,84 \mathrm{a} \pm 0,01 *$ & $0,29 \mathrm{a} \pm 0,03 *$ & $3,47 \mathrm{a} \pm 0,15^{*}$ & $9,27 \mathrm{~b} \pm 0,67^{*}$ & $45,38 \mathrm{a} \pm 2,89^{*}$ \\
\hline $\begin{array}{l}\text { Cilindro } \\
\text { Central }\end{array}$ & $\begin{array}{l}92,72 \\
0,72 *\end{array} \quad$ b $\quad$ & $0,19 \mathrm{c} \pm 0,02^{*}$ & $0,39 \mathrm{c} \pm 0,03 *$ & $0,18 \mathrm{~b} \pm 0,006^{*}$ & $0,00 \mathrm{c} \pm 0,0^{*}$ & $6,50 \mathrm{c} \pm 0,76^{*}$ & $29,15 \mathrm{~b} \pm 2,98^{*}$ \\
\hline
\end{tabular}

Médias seguidas de pelo menos uma mesma letra na coluna, não diferem significativamente entre si $(\mathrm{P}<0,05)$. *Erro padrão da média (n=4). Fonte: Lima (2017).

Nessa figura é possível verificar as diferenças consideráveis entre si, nos teores médios de fração de cinza, nos quais a casca apontou o maior teor de cinza em que se distingue dos achados, em que nele encontra-se abaixo do valor de 1,03 g.100g1. De acordo com Gondim et al., (2005), os teores médios de proteína bruta é 1,45 e 1 g.100g-1, apresenta desigualdade estatística em que a casca e polpa apresentam os maiores teores, 0,84 e 0,64 g.100g-1, respectivamente. Os teores de extrato etéreo apontados na figura 2 expressaram divergência estatística, no qual os maiores teores são da polpa e casca, em que a polpa conteve um menor teor ( 0 g.100g-1) e a casca um maior (0,55 g.100g-1) (Gondim et al., 2005).

No entanto, ocorreu desigualdade estatística, no que se refere aos teores de fibras alimentares (Figura 3), em que os teores identificados na casca foram superiores aos outros produtos, logo os relatados por Gondim et al., (2005), da casca e polpa são inferiores, apresentando 3,89 e 1 g.100g-1, respectivamente. Os dados dos índices de calorias e carboidratos também apontaram diferença estatística, tendo maior valor na polpa, em que apresenta maiores teores de carboidratos e calorias na casca do abacaxi.

Na avaliação da composição centesimal da casca de abacaxi, Santos et al., (2010) destacaram valores médios de 0,3\% de lipídios, 1,08\% de proteínas e 2,06\% de fibras. Segundo os autores esses índices tornam este subproduto muito atraente para o consumo humano utilizados, por exemplo, no fornecimento de aminoácidos essenciais pelo seu teor protéico e como fonte alternativa de fibra alimentar. Constitui-se como um suplemento alimentar de baixo valor nutritivo, pesquisadores apontaram taxas mais elevadas na casca e no bagaço de abacaxi, com valores de fibra insolúvel e solúvel de 7,52\% e 5,89\%, respectivamente (Costa et al., 2007). Conforme Brasil (2012), alimentos com teor mínimo de fibra alimentar de 3\% podem ser apontados como uma boa fonte.

Essas fibras são encontradas de forma natural em verduras, legumes e hortaliças, frutos secos, frutas secas e desidratadas, cereais de grãos inteiros e artigos preparados com estes alimentos, podendo adicioná-las de forma artificial, melhorando alimentos como pães, biscoitos, outros cereais e mais alguns laticínios (Arabbi, 2001). Mendeset al., (2013) realizou um estudo sobre a composição da fibra alimentar presente na casca de abacaxi e do cilindro central, e concluíram que ambos são considerados boa fonte de fibra insolúvel (celulose, hemicelulose e lignina), todavia são carentes em solúvel, como a pectina. Logo, a casca revelou maiores teores de fibra insolúvel e solúvel do que o presente no cilindro central da fruta.

\subsection{Resíduos do abacaxi}

Segundo Gondim et al., (2005) o Brasil enfrenta problemas como a fome e o desperdício de alimentos, sendo este um dos paradoxos do país. Isso ocorre por não conter o hábito alimentar de utilizar folhas, talos de hortaliças e cascas de frutas, e por falta de informação que a população necessita para consumir esses alimentos que contém nutrientes como carboidratos, 
vitaminas, proteínas e fibras presentes em quantidades superiores a da polpa, reduzindo o desperdício da comida jogada no lixo e consequentemente os gastos com a alimentação e aperfeiçoamento da qualidade nutricional do menu (Lima, 2017). Sanjairaj et al., (2012), reconhece que um dos desafios da atualidade é a busca pela redução de despesas de alimentos que acontece ao longo da elaboração, coleta, pós-coleta e comercialização. A secagem é citada pelos autores como um procedimento eficaz para que decorra nessa diminuição.

A indústria do abacaxi é famosa por gerar grandes quantidades de resíduos sólidos, considerando que apenas $25 \%$ da fruta é utilizada como produto comercializável (Abrel et al., 2019). Somente os caules das frutas representam $20 \%$ do total são gerados pela indústria de processamento do fruto (Campos et al., 2019).

Os principais resíduos do abacaxi menos processado são a coroa, casca, a extremidade e cilindro central. O peso da casca do abacaxi "pérola" corresponde ao peso do cilindro central e, corresponde, por 38\% do peso total (Sarzi et al. 2002). Conforme Ribeiro et al., (2011), o produto das porções polpa, casca e cilindro central de abacaxi "pérola" é de 44,10\%, 18,96\% e 14,58\%, respectivamente. As cascas, talos, coroas e cilindros do abacaxi são considerados rejeitos pela indústria de celulose e se destacam por seu alto teor de açúcar (especialmente pectina), fibra e razoável teor de proteína. A parte comestível representa 22,5\% a 35\% da fruta, e o restante é geralmente descartado após o processamento industrial (Rogério et al., 2004).

$\mathrm{O}$ aproveitamento industrial do abacaxi ainda é baixo frente ao seu consumo in natura, devendo ser feito buscas de alternativas para o seu uso, planejando o aproveitamento em excesso de safras, sobretudo pela indústria, para a fabricação de produtos não tradicionais (Araújo et al., 2009). Dessa forma, é possível usar os resíduos para o animal e descartá-lo no solo, como fertilizantes, porém essas opções não utilizam totalmente seu potencial (Gil \& Maupoey, 2018; Siti Rocha et al., 2013).

A casca de abacaxi contém um teor de nutrientes mais alto que a polpa, na qual o conteúdo mineral é responsável por cerca de 4,74\%, e o teor de fibra alimentar é responsável por cerca de 17,92\% (Neres, Souza E Bezerra, 2015). Através de outros estudos, constatou-se que a casca apresenta lipídios, fibras, cálcio, proteínas e potássio a mais do que existente na polpa (Gondim et al., 2005). A utilidade dela na alimentação humana é uma boa alternativa para o reaproveitamento do fruto, pois contém proporções aproximadas às da polpa de proteína bruta, lipídios e matéria mineral e um maior teor de fibras e menor valor calórico (Lima et al., 2017).

Em concordância com os resultados e o aumento da porcentagem da casca elaborada no seguimento ocorre a possibilidade de uma melhor opção de exploração deste resíduo, empregado na confecção de doces, visto que é composta pelo teor de fibras e de nutrientes, como apontado por Lima et al., (2017). De acordo com Santiniet al., (2013), essa apresenta abundantes nutrientes, como lipídeos, proteínas, vitamina $\mathrm{C}$, fibras, potássio, fósforo e cálcio quando comparado a polpa. Aplicando-o a casca de abacaxi na produção de geleia (Santiniet al., 2013), bolo (Martin et al., 2012) e farinha (Moreno, 2016).

A casca do abacaxi apresenta ação antioxidante, atua como anti-inflamatório e auxilia na digestão dos alimentos, além de conter grande aceitação sensorial por parte dos consumidores (Manetti, 2009). O Brasil obteve um grande potencial na pesquisa de novos alimentos, nem sempre são tradicionais, mas são relevantes em termos de valor nutricional e são melhores explorados (Lucio, Freitas e Waszczynskyj, 2010). Dentre esses, o abacaxi é uma fruta que seu valor nutritivo é o valor energético, devido a sua composição de carboidrato. Os teores de proteína e de matéria graxa são inferiores a $0,5 \%$, apresentando baixa fonte de vitamina $\mathrm{C}$ em relação a outras fontes. Além de não apresentar outros nutrientes em quantidades significativas, o mesmo merece destaque pela sua atividade proteolítica, que se estabelece como coadjuvante da digestão dos alimentos e, da mesma forma, como matéria-prima para a extração da enzima bromelina, que têm uma extensa aplicabilidade na indústria de alimentos (Pecosch, 2011). 


\subsection{Aplicações Terapêuticas da Bromelina}

O abacaxi é utilizado como planta medicinal em muitas culturas locais, mas a bromelina não era conhecida quimicamente até 1856. No entanto, como produto farmacêutico industrial, manufaturou-se pela primeira vez no Havaí em 1956. Desde então, diversos trabalhos científicos são dedicados à descrição de várias atividades farmacológicas desta protease (Maurer, 2001; Hale et al., 2002). Mesmo antes da Bromelina ser quimicamente conhecida em 1876, o abacaxi já era utilizado como planta medicinal em diversas culturas naturas (Maurer, 2001; Hale et al., 2002). A sua importância econômica atraiu a atenção das pessoas por estar relacionada às drogas e a sua produção. É utilizado na indústria alimentar para clarificar cerveja, produzir queijo, amaciar carne, preparar alimentos para bebês e dietas e para doenças do sistema digestivo, feridas e inflamações e amolecimento de fibras na indústria têxtil (França, 2009).

As enzimas proteolíticas contêm como principal função biológica a hidrólise de proteínas e participam do processo de digestão, ativação enzimática, coagulação sanguínea entre outros (César, 2005). O uso da bromelina é fundamentado em sua atividade proteolítica na indústria de alimentos e essencialmente na farmacêutica brasileira (Ferreira, 2007). O efeito é documentado, pois além de ser eficaz em alguns problemas de saúde, também é absorvido pela via oral e há evidências de que a atividade terapêutica da enzima aumenta com o aumento de doses. Embora todos os seus mecanismos de ação ainda não sejam totalmente compreendidos, provou-se ser um complemento seguro e eficaz (Cesar, 2005).

A bromelina é encontrada no abacaxizeiro e em outras espécies de plantas da família Bromeliaceae, que mostram efeitos anti-sanguíneos, anti-inflamatórios, anti-trombose e fibrinolítica, em in vitro e in vivo. Na literatura essa enzima, estudou-se pela primeira vez por Marcano em 1981 que a descreveu como digestiva ao analisar o suco de abacaxi (Maurer, 2001; Silva, 2013). Esta é um tipo de proteína digestiva e pode ser classificada como protease. A protease pertence a um grupo de enzimas com função catalítica de hidrolisarem as ligações peptídicas de proteínas (Abrelet al., 2019; Ribeiro, 2020). A sua funcionalidade é semelhante à papaína e à ficina e sua atividade dependem do grupo tiol de um resíduo de cisteína no seu sítio ativo (Amidet al., 2011). Nos estágios iniciais a Bromelina não está presente no desenvolvimento do fruto, no entanto, ocorre o aumento e a permanência do seu nível até amadurecer. Após o amadurecimento, os níveis diminuem rapidamente. Comparado com outras plantas, essa é uma das vantagens do uso do abacaxi como fonte de protease, pois mesmo no estágio maduro, o abacaxi é a única fruta que contém uma maior concentração de protease (Silvestre et al., 2012).

Entre outros fatores, a bromelina é amplamente caracterizada devido à sua importância econômica na produção de medicamentos. No entanto, comparada à demanda do mercado, sua produção ainda é pequena porque não é produzida no Brasil e, portanto, se torna um produto com custo exorbitante (Costa, 2008).

A bromelina é uma enzima que é empregue em diferentes áreas, todas fundamentadas em sua atividade proteolítica, dentre as quais se ressalta a propriedade de facilitar a digestão de proteínas, sua capacidade de amaciamento de carnes e são acrescentada em medicamentos digestivos (Abílio, 2009). Esta enzima proteolítica transforma as matérias albuminóides em proteases ou peptanos, no meio ácido, alcalino e neutro (Borges, 2005; Teixeira, 2013). As enzimas digestivas ajudam e aceleram os processos químicos correlacionados à digestão. Na maioria dos casos, o corpo produz espontaneamente enzimas que podem digerir os alimentos. No entanto, pessoas com certas condições e doenças de saúde podem precisar de suplementos para fornecer enzimas que auxiliam na digestão (Silva, 2013).

No caso de enzima digestiva para insuficiência exócrina do pâncreas e outras doenças intestinais, trabalha em uma ampla faixa de $\mathrm{pH}$, possui atividade no estômago e no intestino. Na ausência dessas, os fatos provaram que pode substituir completamente a pepsina e a tripsina (Silva,2008). Essa é obtida a partir de suas partes não comestíveis, consideradas como resíduo industrial (Noret al., 2016). A mesma vem sendo amplamente utilizada na indústria farmacêutica como agente ativo para o tratamento de doenças inflamatórias, intestinais e doenças relacionadas à coagulação (Noret al., 2015), agente 
fibrinolítico (Chaurasiya; Hebbar, 2013), tratamento oral de queimaduras de terceiro grau (Bernela et al. 2016), aplicação terapêutica de anticorpos (Abrelet al., 2019) e ação mucolítica (Costa et al., 2014).

Ainda são necessários maiores estudos sobre os seus mecanismos de ação, contudo demonstrado que o mesmo é um seguro e efetivo suplemento. De acordo com estudos a bromelina parece conter ação direta e indireta, envolvendo os sistemas enzimáticos, ao exercer seus efeitos anti-inflamatórios, indigestão, problemas respiratórios e angina (César, 2005; Ferreira et al., 2011).

O abacaxi é utilizado como alimento, porém bastante usado na medicina popular, por ser reconhecida suas propriedades medicinais como carmitativo, anti-inflamatório e estomáquio, indicados para problemas das vias respiratórias e para neurastenia. É usado em vários países para atender necessidades variadas, como: na Tailândia no tratamento da disúria; na China, no córtex serve como agente alexifármaco, antitussivo e antidiarreico, e suas folhas são regularmente empregues como agente contra a dispepsia e antidiarreico; na Índia, conta-se que o suco das folhas e frutos verdes apresenta atividade antihelmíntica e propriedades abortivas. Os estudos realizados dos extratos etanólicos das folhas de Ananascomosus apresentaram efeitos antidiabético, anti-hiperlipidimêmico e antioxidante. Outras atividades que são sugeridas para o abacaxi são as propriedades: depurativa, anti-inflamatória, antioxidante, proteolítica e tônica (Manetti, 2009).

\subsection{Agente anti-inflamatório}

Os estudos demonstram que a eficácia da bromelina como anti-inflamatório é similar à dos anti-inflamatórios convencionais como os AINES (anti-inflamatórios não esteroidais), que são usados para combater os sinais clássicos de inflamação (febre, dor, rubor e tumores). Além disso, evidenciaram que a enzima contém a capacidade de reduzir efetivamente a IL-8 (uma citocina importante no processo inflamatório) induzida pela migração de neutrófilos in vitro e in vivo (Hale, 2005).

Através da bromelina confirmaram-se os efeitos terapêuticos benéficos em inúmeras experiências in vitro, que apresentou a redução de mediadores inflamatórios por células imunes (Silva, 2008). Estes efeitos vêm sendo testados em humanos ou animais que apresentam doenças inflamatórias do intestino, assim como artrites. Contudo, são necessários maiores estudos para entender como cada proteinase dentro do complexo de bromelina contribui em seus efeitos inflamatórios in vivo (Haleet al., 2005).

\subsection{Antitumoral}

A bromelina contém atividade antimetastática, podendo estimular uma variedade de caspases e promover a apoptose celular. No tratamento do câncer, o seu uso reduz o tamanho do tumor e os danos às células saudáveis, causando menos efeitos posteriores em comparação à quimioterapia (Bhuiet al., 2009; Aminiet al., 2016). Essa sucede consideravelmente a regressão do tumor em certas linhas celulares, como leucemia P-388, sarcoma (S-37), carcinoma de células escamosas A-431, melanoma A-375, câncer de pulmão Lewis (BATKIN et al., 1988) e câncer de mama ADC-755 (Bhuiet al., 2012; Pavan et al., 2012).

Através das pesquisas exemplificou-se a diminuição na proliferação in vitro, em linhagens de células contra o carcinoma epidermóide humano A431 e células de melanoma (Bhui, 2012). Vários estudos comprovam que a enzima presente no abacaxi possui efeitos anticancerígenos, além de que o seu uso em junção com medicamentos quimioterápicos aumenta a eficiência dessas drogas em certa proporção (Pillai et al., 2013; Amini et al., 2014).

\subsection{Trato Gastrointestinal}

As enzimas digestivas auxiliam e estimulam os processos químicos relacionados com a digestão. Na maior parte dos casos, o corpo humano espontaneamente fornece enzimas que são capazes de digerir alimentos. Contudo, as pessoas com certas condições de saúde e complicações podem solicitar a utilização de suplementos para fornecer as enzimas que ajudam na 
digestão (Silva, 2013). A bromelina é uma enzima protease que é capaz de estimular os músculos das paredes intestinais, além de ser auxiliar na digestão de proteínas e constantemente inserida como componente importante em variados suplementos de enzimas digestivas (Teixeira, 2013).

O acréscimo no consumo de fibra alimentar é frequentemente usado na prevenção e no tratamento da constipação. Os cereais integrais, os suplementos de fibras e o farelo de trigo, são abundantemente usufruídos pelos consumidores, o que mostra o conhecimento comum das pessoas sobre os efeitos benéficos das fibras (Anderson et al., 2009). De acordo com os estudos desenvolvidos por Bharucha et al. (2013), a obstipação intestinal ou constipação, é uma síndrome baseada em sintomas, não caracteriza-se como enfermidade, mas como complicação e diminuição dos movimentos intestinais.

De acordo com Anjo (2004), a utilização das fibras possui como efeito a diminuição dos níveis de colesterol sanguíneo e dos riscos de progresso do câncer, por meio das causas: redução do tempo do trânsito intestinal, promovendo uma rápida eliminação do bolo fecal, com redução do tempo de contato do tecido intestinal com substâncias mutagênicas e carcinogênicas e formação de substâncias protetoras pela fermentação bacteriana dos compostos de alimentação; capacidade de retenção de substâncias tóxicas ingeridas ou produzidas no trato gastrointestinal durante processos digestivos (Moraes, 2006).

\subsection{Inibidor de Formação de Trombo}

De acordo com pesquisas envolvendo o processo de hemostasia, ou seja, envolvendo a coagulação do sangue e agregação de plaquetas, já ocorreram com cisteíno-proteases presente na bromelina (Bilheiro, 2012). A enzima dispõe de atividades antitrombótica, anticoagulantes e diminui a agregação plaquetária, além de que impede o agrupamento de plaquetas, impossibilitando a formação de trombos e proíbe a fixação de plaquetas ao endotélio. Possui a capacidade de reduzir a angina e dispõe de ação anti-hipertensiva (Silva, 2008; Bhatacharia, 2008). Observou-se em um modelo in vivo de trombose induzida por laser em ratos, que a administração oral reduziu a trombose arteriolar em $11 \%$ além de que no in vitro a bromelina mostrou ser apta para ativar o plasminogênio, que forma a plasmina, do qual é o principal fibrinolítico endógeno (Bilheiro, 2012).

\subsection{Queimaduras}

O desbridamento é o ato de eliminar o tecido morto, infectado ou danificado no local da escara, a fim de promover o potencial de cura dos tecidos saudáveis restantes (Rosenberg et al., 2012). Alguns pesquisadores expuseram que a bromelina é utilizada na cura de feridas pós-cirúrgicas e ajuda a reduzir o inchaço e a dor, etc. (Graf, 2000; Mackayand Miller, 2003).

A aplicação local da bromelina se mostrou eficaz, não invasivo, podendo ser facilmente realizada e se envolve de maneira insignificante nos processos naturais de cicatrização eficaz para a remoção do tecido necrótico, e é uma alternativa ao desbridamento cirúrgico (Cordtset al., 2016; Krieger et al., 2012; Kolleret al., 2008). Apontada no tratamento de feridas cutâneas, por causa do seu poder fibrinolítico que opera acelerando o desenvolvimento do tecido de granulação e em sequência a cicatrização de lesões (Oliveira, 2001).

\subsection{Agente Mucolítica}

A bromelina possibilita uma melhor fluidificação das secreções mucosas, que ocorre por meio da ação da enzima que catalisa a quebra de ligações entre as ligações peptídicas pela integração de moléculas de água contribuindo assim, para a fluidificação do muco espesso (Cesar, 2005). Essa certificou sua capacidade de reduzir a viscosidade de secreções mucosas respiratórias por meio da sua atividade proteolítica e através de atividade tiol-redutase, proporcionando a quebra das pontes dissulfeto inter e intracadeias de mucina, reduzindo as ligações responsáveis pela formação da malha de mucina, atividade similar à N-acetilcisteína (King \& Rubin, 2002). 
Atua na diminuição das doenças alérgicas respiratórias podendo ser utilizada no tratamento da asma (Secor Jret al., 2005). Alguns experimentos apresentaram, in vitro, ação mucolítica e fluidificante da bromelina sobre secreç̃os brônquicas (Silva, 2008). Esse agente mucolítico é eficaz e utilizado de modo efetivo para rinite, rinossinusite e rinossinusite crônica (Guo et al., 2006; Büttner et al., 2013). Ademais, reduz a formação de prostaglandinas pró-inflamatórias e diminui o inchaço das passagens nasais (Helms, Miller 2006).

\section{Conclusão}

O abacaxi é uma fruta de destaque pela sua atividade proteolítica que se estabelece como coadjuvante da digestão dos alimentos em virtude da presença da bromelina. Na atualidade o abacaxi e em sua casca apresentam diversos efeitos benéficos de usos terapêuticos, tais como: ação anti-inflamatórias, ação antitumoral, atividade fibrinolítica, inibição da agregação plaquetária, modulação de citocinas e da imunidade, propriedade debridande de pele, aumento da absorção de outras drogas, propriedades mucolíticas, facilitador da digestão, acelerador da cicatrização e do sistema cardiovascular, bem como da melhoria da circulação.

Esta revisão narrativa torna evidente o potencial da casca do abacaxi como alimento funcional. Até este momento existe uma limitada quantidade de estudos com este enfoque, a partir disso são necessários maiores estudos para poder comprovar o resíduo como um alimento funcional.

\section{Referências}

Abílio, G. M. F., Holschuh, H. J., Bora, P. S., \& Oliveira, E. F. (2009). Extração, atividade da bromelina e análise de alguns parâmetros químicos em cultivares de abacaxi. Revista Brasileira de Fruticultura., 31(4), 1117-1121. https://doi.org/10.1590/S0100-29452009000400027

Abreu, D. C. A., \& Figueiredo, K. C. de S. (2019). Bromelain separation and purification processes from pineapple extract. Brazilian Journal of Chemical Engineering. 36(2), 1029-1039. https://doi.org/10.1590/0104-6632.20190362s20180417

Alexandre, H. V. Da Silva, F. L. H Gomes, J. P. Silva, O. S. \& Carvalho, J. P. (2015). Isotermas de dessorção de resíduos de abacaxi. In: XX Congresso Brasileiro de Engenharia Química - COBEQ, 2014. São Paulo. Anais. Blucher, 3472-3479. 10.5151/chemeng-cobeq2014-0422-25562-181058

Amid, A., Ismail, N. A., Yusof, F., \& Salleh, H. M. (2011). Expression, purification, and characterization of a recombinantstem bromelain. Process Biochemistry, 46, 2232-2239, 2011. https://www.sciencedirect.com/science/article/abs/pii/S1359511311002935

Amini, A., Moghaddam, S. M., Ehteda, A., \& Morris, L. (2014). Bromelainand N-acetyl cysteine inhibit the proliferation and survival of gastrointestinal cancercells in vitro: the meaning of combination therapy. Journal of Experimental and Clinical Cancer Research, 33 (1): 92. https://doi.org/10.1186/s13046014-0092-7

Amini, A., Masoumi-Moghaddam, S., \& Morris, D. L. Bromelaína. In: Utilidade de Bromelaína e N-Acetilcisteína no Tratamento da Disseminação Peritoneal de Malignidades Produtoras de Mucina Gastrointestinal. Suíça: publicação internacional Springer, 63-80. 10.1007/978-3-319-28570-2

Anderson, J. W., Baird, P., Davis, R. H., Jr, Ferreri, S., Knudtson, M., Koraym, A., Waters, V., \& Williams, C. L. (2009). Health benefits of dietary fiber. Nutrition reviews, 67(4), 188-205. https://doi.org/10.1111/j.1753-4887.2009.00189.x

Anjo, D. L. C. (2004). Alimentos funcionais em angiologia e cirurgia vascular. Jornal Vascular Brasileiro 3(2), 145-154, https://www.jvascbras.org/article/5e1f5f740e88256a3dd8495a/pdf/jvb-3-2-145.pdf

Arabbi, P. R. (2001). Alimentos funcionais - aspectos gerais. Revista Nutrire. 21,87-102, http://sban.cloudpainel.com.br/files/revistas_publicacoes/18.pdf

Batkin, S., Taussig, S. J., \& Szekerezes, J. (1988). Antimetastatic effect of bromelain with or without its proteolytic and anticoagulant activity. Journal of cancer research and clinical oncology, 114(5), 507-508. https://doi.org/10.1007/BF00391501

Bharucha, A. E., Pemberton, J. H., \& Locke, G. R., 3rd (2013). American Gastroenterological Association technical review on constipation. Gastroenterology, 144(1), 218-238. https://doi.org/10.1053/j.gastro.2012.10.028

Bhattacharya, S., Zoladek, T., \& Haines, D. S. (2008). WW domains 2 and 3 of Rsp5p play overlapping roles in binding to the LPKY motif of Spt23p and Mga2p. The international journal of biochemistry cell biology, 40(1), 147-157. https://doi.org/10.1016/j.biocel.2007.07.007

Bengozi, F. J., Sampaio, A. C., Spoto, M. H. F., Mischan, M. M., \& Pallamin, M. L. (2007). Qualidades físicas e químicas do abacaxi comercializado na CEAGESP São Paulo. Revista Brasileira de Fruticultura 29(3), 540-545. https://doi.org/10.1590/S0100-29452007000300025>

Benzing, D. H., Bennett, B., Brown, G., Dimmitt, M., Luther, H., Ramirez, I., Terry, R., \& Till, W. (2000). Bromeliaceae: profile of an adaptive radiation. New York: Cambridge University, 690p. 10.1017/CBO9780511565175. 
Bernela, M., Ahuja, M., \& Thakur, R. (2016). Enhancement of anti-inflammatory activity of bromelain by its encapsulation in katira gum nanoparticles. Carbohydrate polymers, 143, 18-24. https://doi.org/10.1016/j.carbpol.2016.01.055

Bilheiro, R. P. (2012). Fração PlG10 do látex de Vasconcellea cundinamarcensis: atividade antitrombótica in vivo e anticoagulante/antiagregante plaquetária in vitro. Dissertação de Mestrado apresentada ao Programa de Pós-graduação em Ciências Biológicas. Universidade Federal de Minas Gerais. Belo Horizonte. https://repositorio.ufmg.br/bitstream/1843/BUOS-8UAJ6Y/1/dissertacao_de_mestrado_rogerio_bilheiro.pdf

Borges, C., Chim, J., Leitão, A., Pereira, E., \& Luvielmo, M. (2005). Produção de suco de abacaxi obtido a partir dos resíduos da indústria conserveira. Boletim do Centro de Pesquisa de Processamento de Alimentos. 22. 10.5380/cep.v22i1.1177. http://dx.doi.org/10.5380/cep.v22i1.1177

Brasil. (2012). Ministério da Saúde. Agência Nacional de Vigilância Sanitária. Resolução n ${ }^{\circ}$ 54, de 12 de novembro de 2012 - Regulamento técnico sobre informação nutricional complementar. Brasilia, DF: Diário Oficial [da] República Federativa do Brasil, Poder Executivo. https://bvsms.saude.gov.br/bvs/saudelegis/anvisa/2012/rdc0054_12_11_2012.html\#: :text=O\%20presente\%20Regulamento\%20T\%C3\%A9cnico\%20se,e\%20 prontos\%20para\%20oferta\%20aos

Brito, C. A. K., Siqueira, P. B., Pio, T. F., Bolini, H. M. A., \& Sato, H. H. (2008). Caracterização físico-química, enzimática e aceitação sensorial de três cultivares de abacaxi. Revista Brasileira de Tecnologia Agroindustrial, 2(2), 10.3895/S1981-36862008000200001

Bhui, K., Prasad, S. George, J., \& Shukla, Y. (2009). Bromelain inhibits COX-2 expression by blocking the activation of MAPK regulated NF-kappa B against skin tumor-initiation triggering mitochondrial death pathway. Cancer letters, 282(2), 167-176. https://doi.org/10.1016/j.canlet.2009.03.003

Bhui, K., Tyagi, S., Srivastava, A. K., Singh, M., Roy, P., Singh, R., \& Shukla, Y. (2012). Bromelain inhibits nuclear factor kappa-B translocation, driving human epidermoid carcinoma A431 and melanoma A375 cells through $\mathrm{G}(2) / \mathrm{M}$ arrest to apoptosis. Molecular carcinogenesis, 51(3), 231-243. https://doi.org/10.1002/mc.20769

Büttner, L., Achilles, N., Böhm, M., Shah-Hosseini, K., \& Mösges, R. (2013). Efficacy and tolerability of bromelain in patients with chronic rhinosinusitis--a pilot study. B-ENT, 9(3), 217-225. https://pubmed.ncbi.nlm.nih.gov/24273953/

Campos, D. A., Coscueta, E. R., Valetti, N. W., Pastrana-Castro, L. M., Teixeira, J. A., Picó, G. A., \& Pintado, M. M. (2019). Optimization of bromelain isolation from pineapple byproducts by polysaccharide complex formation. Food Hydrocolloids, 87, 792-804. https://doi.org/10.1016/j.foodhyd.2018.09.009

Casemiro, I. P., \& Ramos, P. (2014). Produção científica sobre alimentos funcionais: uma análise das publicações brasileiras entre 2007 e 2013. Demetra: alimentação, nutrição saúde, 9(4), 925-941. http://dx.doi.org/10.12957/demetra.2014.11608

Cesar, A. C. W. (2005). Análise de viabilidade econômica de um processo de extração de purificação da bromelina do abacaxi. Tese (Doutorado em Engenharia Química) - Faculdade de Engenharia Química, Universidade Estadual de Campinas, 2005. http://repositorio.unicamp.br/jspui/handle/REPOSIP/267439

Chaurasiya, R. S., \& Hebbar, H. U. (2013). Extraction Of Bromelain From Pineapple Core And Purification By Rme And Precipitation Methods. Separation And Purification Techology, 111,90-97, 2013. Https://Doi.Org/10.1016/J.Seppur.2013.03.029

Chaves, A. C. C., Yassin, L. S., Mendes, C. A. P., Borsato, A. V., \& Raupp, D. S. (2015). Development of light pineapple jam with propolis. Revista Journal of Health. 14 a Edição. Jul-dez. 2015. https://www.alice.cnptia.embrapa.br/alice/bitstream/doc/1033594/1/92015JofHealthv14juldezp7088.pdf

Costa, J. M. C., Felipe, E. M. F., Maia, G. A., Brasil, I. M. \& Hernandez, F. F. H. (2007). Comparação dos parâmetros físico-químicos e químicos de pós alimentícios obtidos de resíduos de abacaxi. Revista Ciência Agronômica, 38(2), 228-232. http://ccarevista.ufc.br/seer/index.php/ccarevista/article/view/141

Cordts, T., Horter, J., Vogelpohl, J., Kremer, T., Kneser, U., \& Hernekamp, J. F. (2016). Enzymatic debridement for the treatment of severely burned upper extremities - early single center experiences. BMC dermatology, 16(1), 8. https://doi.org/10.1186/s12895-016-0045-2

Costa, H. B., Fernandes, P. M. B., \& Ventura, J. A. (2008). Extração, purificação parcial e comparação de duas técnicas de precipitação de enzimas proteolíticas do abacaxizeiro. XX Congresso Brasileiro de fruticultura, Vitória: Espírito Santo, 2008. https://biblioteca.incaper.es.gov.br/digital/bitstream/item/180/1/extracao-purificacao-parcial-e-comparacao-de-duas-tecnicas-de-precipitacao-de-enzimasproteoliticas-do-abacaxizeiro-cd-anaissmallpdf.com.pdf

Costa, H. B., Fernandes, P. M., Romão, W., \& Ventura, J. A. (2014). A New Procedure Based On Column Chromatography To Purify Bromelain By Ion Exchange Plus Gel Filtration Chromatographies. Industrial Crops And Products, 59, 163-168, 2014. Https://Doi.Org/10.1016/J.Indcrop.2014.04.042

Costa, J. R. G., Brito, F. A. L., Oliveira, K. S., de Oliveira, M. M., Oliveira, T. F. F., \& de Oliveira, L. L. (2016). Educação em saúde sobre atenção alimentar: uma estratégia de intervenção em enfermagem aos portadores de diabetes mellitus. Mostra Interdisciplinar do curso de Enfermagem. 2(1). https://publicacoesacademicas.unicatolicaquixada.edu.br/index.php/mice/article/view/1111

Colpo, E., Fuke, G., \& Zimmermann, M. M. (2016). Consumo de alimentos funcionais em unidades de alimentação e nutrição de Santa Maria/RS. Disciplinarum Scientia Saúde. 5(1), 69-83. https://periodicos.ufn.edu.br/index.php/disciplinarumS/article/view/886

Crestani, M., Barbieri, R. L., Hawerrothl, F. J., Carvalho, F. I. F., \& Oliveira, A. C. (2010). Das Américas para o Mundo - origem, domesticação e dispersão do abacaxizeiro. Ciência Rural, 40(6), 1473-1483. https://www.scielo.br/j/cr/a/NRpbBs3Tm9D3CMhMVsVNTHJ/?lang=pt\&format=pdf

Faria, D. C. (2008). Desenvolvimento e produtividade do abacaxizeiro 'smoothcayenne' em função de adubação nitrogenada e tipos de mudas no norte fluminense. Campos dos Goytacazes. Tese (Centro de Ciências e Tecnologias Agropecuárias) - Universidade Estadual do Norte Fluminense Darcy Ribeiro. http://livros01.livrosgratis.com.br/cp052131.pdf

Ferreira, J. F. (2007). Caracterização e purificação da enzima bromelina em sistema de duas fases aquosas PEG/Fosfato. 83f. Dissertação (mestrado) Universidade Estadual de Campinas, Faculdade de Engenharia Quimica, Campinas, SP. http://www.repositorio.unicamp.br/handle/REPOSIP/266254 
Ferreira, J. F. Sbruzzi, D. B., Kleber M., \& Isaac T., E. (2011). Purificação da enzima bromelina presente no curauá (Ananas erectifolius L.B. SMITH) variedade roxa, por sistema bifásico aquoso peg 4000/fosfato de potássio. Revista Brasileira de Produtos Agroindustriais. 13. 197-202. 10.15871/15178595/rbpa.v13n2p197-202.

França, A. S., Alves, R. S., Leite, N. S., \& Fernandes, R. P. M. (2009). Estudos bioquímicos da enzima bromelina do Ananascomosus (abacaxi). Scientia Plena, v. 5, no 11, 2009. https://scientiaplena.emnuvens.com.br/sp/article/view/749

Food And Agriculture Organization Of The United Nations - Fao. (2013). http://faostat.fao.org/site/567/DesktopDefault.aspx?PageID=567>.

Gil, L. S., \& Maupoey, P. F. (2018). An integrated approach for pineapple waste valorisation. Bioethanol production and bromelain extraction from pineapple residues. Journal of Cleaner Production, 172, 1224-1231. https://doi.org/10.1016/j.jclepro.2017.10.284

Góes, L. B. (2008). Alimentos Funcionais: Uma Alternativa Nutricional? 21f, Trabalho de Conclusão de Curso (Curso de Nutrição) - Faculdade Assis Gurgacz - FAG, 2008.

Gondim, J. A. M., Moura, M. F. V., Dantas, A. S., Medeiros, R. L. S., \& Santos, K. M. (2005). Composição centesimal e de minerais em cascas de frutas. Ciência e Tecnologia de Alimentos, 25(4), 825-827. https://www.scielo.br/j/cta/a/kMcMJSY8RXPcF99CGD7PqWL/?format=pdf\&lang=pt

Graf J. (2000). Herbal anti-inflammatory agents for skin disease. Skin therapy letter, 5(4), 3-5. https://pubmed.ncbi.nlm.nih.gov/10785407/

Granada, G., Zambiazi, R., \& Mendonça, C. (2005). Abacaxi: produção, mercado e subprodutos. Boletim do Centro de Pesquisa de Processamento de Alimentos. 22. 10.5380/cep.v22i2.1203.

Guo, R., Canter, P. H., \& Ernst, E. (2006). Herbal medicines for the treatment of rhinosinusitis: a systematic review. Otolaryngology--head and neck surgery : official journal of American Academy of Otolaryngology-Head and Neck Surgery, 135(4), 496-506. https://doi.org/10.1016/j.otohns.2006.06.1254

Hale, L. P., Greer, P. K., \& Sempowski, G. D. (2002). Bromelain treatment alters leukocyte expression of cell surface molecules involved in cellular adhesion and activation. Clinical immunology (Orlando, Fla.), 104(2), 183-190. https://doi.org/10.1006/clim.2002.5254

Hale, L. P., Greer, P. K., Trinh, C. T., \& James, C. L. (2005). Proteinase activity and stability of natural bromelain preparations. International immunopharmacology, 5(4), 783-793. https://doi.org/10.1016/j.intimp.2004.12.007

Hale, L. P., Greer, P. K., Trinh, C. T., \& Gottfried, M. R. (2005). Treatment with oral bromelain decreases colonic inflammation in the IL-10-deficient murine model of inflammatory bowel disease. Clinical immunology (Orlando, Fla.), 116(2), 135-142. https://doi.org/10.1016/j.clim.2005.04.011

Helms, S., \& Miller, A. (2006). Natural treatment of chronic rhinosinusitis. Alternative medicine review: a journal of clinical therapeutic, 11(3), 196-207. https://pubmed.ncbi.nlm.nih.gov/17217321/

Hossain, M. A., \& Rahman, S. M. M. (2011). Total Phenolics, Flavonoids And Antioxidant Activity Of Tropical Fruit Pineapple. Food Research International, 44(3), 672-676, 2011. Https://Doi.Org/10.1016/J.Foodres.2010.11.036

Ikeda, A. A., Moraes, A., \& Mesquista, G. (2010). Considerações sobre tendências e oportunidades dos alimentos funcionais. Revista P\&D em Engenharia de Produção, 8(2), 40-56. http://www.revista-ped.unifei.edu.br/documentos/V08N02/v8n2_artigo_03.pdf

King, M., \& Rubin, B. K. (2002). Pharmacological approaches to discovery and development of new mucolytic agents. Advanced drug delivery reviews, 54(11), 1475-1490. https://doi.org/10.1016/s0169-409x(02)00156-4

Koller, J., Bukovcan, P., Orság, M., Kvalténi, R., \& Gräffinger, I. (2008). Enzymatic necrolysis of acute deep burns--report of preliminary results with 22 patients. Acta chirurgiae plasticae, 50(4), 109-114.https://pubmed.ncbi.nlm.nih.gov/19408486/

Krieger, Y., Bogdanov-Berezovsky, A., Gurfinkel, R., Silberstein, E., Sagi, A., \& Rosenberg, L. (2012). Efficacy of enzymatic debridement of deeply burned hands. Burns: journal of the International Society for Burn Injuries, 38(1), 108-112. https://doi.org/10.1016/j.burns.2011.06.002

Lajolo F. M. (2002). Functional foods: Latin American perspectives. The British journal of nutrition,88 Suppl 2, S145-S150. https://doi.org/10.1079/BJN2002679

Lima, P. C. C., Souza, B. S., Santini, A. T., \& Oliveira, D. C. (2017). Agroindustrial use of waste from minimum processed pineapple 'pérola'. HOLOS. 2.122. 10.15628/holos.2017.5238.

Lima, Í. A., Gomes, H. B., Ramos, A. L. S., Piccoli, R. H., \& Ramos, E. M. (2017). Physical, Chemical And Microbiological Characterization Of Deboned DryCured Ham With Added Lactulose. Brazilian Journal Of Food Technology, 20, Https://Www.Scielo.Br/J/Bjft/A/5tgtylg4nmy4fnqbvxcdgbr/Abstract/?Lang=En .

Licodiedoff, S. Aquino, A. Godoy, R. \& Ledo, C. (2010). Avaliação da sinérese em geléia de abacaxi por meio de análise uni e multivariada. Semina: Ciências Exatas e Tecnológicas. 31. 51. 10.5433/1679-0375.2010v31n1p51.

Lucio, I. B., Freitas, R. J. S., \& Waszczynskyj, N. (2010). Composição físico-química e aceitação sensorial da inflorescência de gengibre orgânico (ZingiberofficinaleRoscoe). Revista Ciência e Tecnologia de Alimentos. $\quad$ Campinas, 30 (3):656. https://www.scielo.br/j/cta/a/KjCgHg6xZtm9JVLJL5yDtVk/abstract/?lang=pt

MacKay, D., \& Miller, A. L. (2003). Nutritional support for wound healing. Alternative medicine review : a journal of clinical therapeutic, 8(4), 359-377. https://pubmed.ncbi.nlm.nih.gov/14653765/\#: :text=Glucosamine\%20appears\%20to\%20be\%20the,wound\%20repair\%20and\%20immune\%20function.

Manetti, L., Delaporte, R. H., \& Jr. A. L. (2009). Metabólitos secundários da família bromeliaceae. Química Nova, 32(7), 1885-1897, https://www.scielo.br/j/qn/a/KkxvncrHz4chcPCrmsPtPQx/?lang=pt\#

Marques, C. G., Alves, R. T., Lee, C. J. Y. P., \& Quaresma, M. V. L. dos S. (2019). Efeito do consumo de Kefir sobre parâmetros bioquímicos relacionados ao Diabetes Mellitus: uma revisão de literatura. Revista Eletrônica Acervo Saúde. (19), 214-214. https://doi.org/10.25248/reas.e214.2019 
Martin, J. G. P., Matta Júnior, M. D., Almeida, M. A., Santos, T., \& Spoto, M. H. F. (2012). Avaliação sensorial de bolo com resíduo de casca de abacaxi para suplementação do teor de fibras. Revista Brasileira de Produtos Agroindustriais, 14(3), 281-287. http://www.deag.ufcg.edu.br/rbpa/rev143/Art14311.pdf

Matsuura, F. C. A. U., \& Rolim, R. B. (2002). Avaliação da adição de suco de acerola em Suco de abacaxi visando à Produção de um "blend" com Alto Teor de vitamina C. Revista Brasileira Fruticultura Jaboticabal, 24(1), 138- 141, https://doi.org/10.1590/S0100-29452002000100030

Mendes, B. A. B. (2013). Obtenção, caracterização e aplicação de farinha das cascas de abacaxi e de manga. Dissertação de Mestrado em Engenharia de Alimentos da Universidade Estadual do Sudoeste da Bahia (UESB). http://www2.uesb.br/ppg/ppgecal/wp-content/uploads/2017/04/BRUNA-BRAGA.pdf

Moraes, F. P., \& Colla, L. M. (2006). Alimentos Funcionais e Nutracêuticos: Definições, Legislação e Benefícios à Saúde. Revista Eletrônica de Farmácia, 3(2) https://doi.org/10.5216/ref.v3i2.2082

Moreno, J. S. (2016). Obtenção, caracterização e aplicação de farinha de resíduos de frutas em cookies. Dissertação de Mestrado no Programa de PósGraduação em Engenharia e Ciência de Alimentos da Universidade Estadual do Sudoeste da Bahia. http://www2.uesb.br/ppg/ppgecal/wpcontent/uploads/2017/04/JOYCE-MORENO.pdf

Mynott, T. L., Crossett, B., \& Prathalingam, S. R. (2002). Proteolytic inhibition of Salmonella enterica serovar typhimurium-induced activation of the mitogen-activated protein kinases ERK and JNK in cultured human intestinal cells. Infection and immunity, 70(1), 86-95. https://doi.org/10.1128/IAI.70.1.8695.2002

Nascente, A. S., Costa, R. S. C. Da, \& Costa, J. N. M. (2005). Cultivo do abacaxi em Rondônia. Porto Velho: Embrapa Rondônia http://sistemasdeprodução.cnptia.embrapa.br/ FontesHTML/Abacaxi/CultivodoAbacaxiRO/index.htm

Nascimento, A. L., \& Rabelo, D. M. (2018). Desenvolvimento e análise sensorial da geleia de polpa e casca de abacaxi com gengibre. Revista Acadêmica Conecta FASP, 1(3), 1-14, 2018. http://revista.fasf.edu.br/index.php/conecta/article/view/98

Neres, J. P. G., Souza, R. L. A., \& Bezerra, C. F. (2015). Iogurte com polpa e farinha da casca do abacaxi. Revista do Instituto de Laticínios Cândido Tostes. Juiz de Fora, 70(5), 262-269, https://doi.org/10.14295/2238-6416.v70i5.465

Nor, M. Z. M., Ramchandran, L., Duke, M., \& Vasiljevic. (2015). Characteristic properties of crude pineapple waste extract for bromelain purification by membrane processing. Journal of Food Science and Technology. 52. 10.1007/s13197-015-1812-5.

Oliveira, L. F. (2001). Os avanços do uso da bromelina nas áreas da alimentação e saúde. Alimentos e Nutrição, 12, 2001. https://www.researchgate.net/publication/49600072_OS_AVANCOS_DO_USO_DA_BROMELINA_NA_AREA_DE_ALIMENTACAO_E_SAUDE/fulltext /0e60c654f0c493afa4b5de94/OS-AVANCOS-DO-USO-DA-BROMELINA-NA-AREA-DE-ALIMENTACAO-E-SAUDE.pdf

Oliveira, G. R., Vieira, L. M., Barcellos, M. D., \& Hoppe, A. (2014). Institutional Barriers for Food Innovation: A Study of the Brazilian Functional Food Industry. Journal Of Operations And Supply Chain Management, 7(1), 1-14, 7 2014. https://www.lume.ufrgs.br/handle/10183/122620

Oliveira, A. S. B. (2014). Estudo da secagem de casca de abacaxi visando desenvolvimento de chá a partir do produto seco. Dissertação (Mestrado - Produção Vegetal) - Universidade Estadual do Norte Fluminense Darcy Ribeiro, Centro de Ciências e Tecnologias Agropecuárias. Campos dos Goytacazes, RJ, 2014. https://uenf.br/posgraduacao/producao-vegetal/wp-content/uploads/sites/10/2015/01/Disserta\%C3\%A7\%C3\%A3o-Vers\%C3\%A3o-Final-Ana-Silvia-Boronide-Oliveira-20150105.pdf

Sebrae. (2016). $O$ cultivo $e$ o mercado do abacaxi. https://www.sebrae.com.br/sites/PortalSebrae/artigos/o-cultivo-e-o-mercado-doabacaxi,71b3438af1c92410VgnVCM100000b272010aRCRD.

Pavan, R., Jain, S., Shraddha, Kumar, A. (2012). Properties and therapeutic application of bromelain: a review. Biotechnology research international, 2012, 976203. https://doi.org/10.1155/2012/976203

Pecosch, A. F., \& Tizon, A. C. (2011). Avaliação e quantificação da vitamina c no blend de abacaxi com acerola. Trabalho de Conclusão de Curso de graduação de Tecnologia em Alimentos da Universidade Tecnológica Federal do Paraná. http://repositorio.roca.utfpr.edu.br/jspui/bitstream/1/25544/1/ PG_COALM_2011_2_01.pdf

Pillai, K., Akhter, J., Chua, T. C., \& Morris, D. L. (2013). Anticancer property of bromelain with therapeutic potential in malignant peritoneal mesothelioma. Cancer investigation, 31(4), 241-250. https://doi.org/10.3109/07357907.2013.784777

Ramli, A. N., Aznan, T. N., \& Illias, R. M. (2017). Bromelain: from production to commercialisation. Journal of the science of food and agriculture, 97(5), 1386-1395. https://doi.org/10.1002/jsfa.8122

Ribeiro, W. S., Barbosa, J. A., Carneiro, G. G., Lucena, H. H., \& Almeida, E. I. B. (2011). Controle do fungo penducular do abacaxi pérola. Revista Brasileira de Produtos Agroindustriais. 13. 1-6. 10.15871/1517-8595/rbpa.v13n1p1-6.

Ribeiro, B. J. S. Filho, E. A. M. \& Frey, J. A. (2020). Os Avanços do Uso da Bromelina nos Efeitos da Cicatrização da Pele e Anti-Inflamatório. Revista Acadêmica Online. 6. 1-13. 10.36238/23595787.artcient.29052020.

Roberfroid, M. (2002). Functional food concept and its application to prebiotics. Digestive and liver disease : official journal of the Italian Society of Gastroenterology and the Italian Association for the Study of the Liver, 34 Suppl 2, S105-S110. https://doi.org/10.1016/s1590-8658(02)80176-1

Rogério, M. C. P., Borges, I., Neiva, J. N. M., Pimentel, J. C. M., Carvalho, F. C., Ponte, T. R., Costa, J. B., \& Catunda, A. G. V. (2004). Valor nutritivo do subproduto da indústria processadora de Abacaxi em dietas para ovinos. Consumo de Nutrientes. $141^{\mathrm{a}}$ Reunião Anual da Sociedade Brasileira de Zootecnia. 2004. http://www.scielo.br/scielo.php?script=sci_arttext\&pid=S010209352007000300032

Rogério, M. C. P., Borges, I., Neiva, J. N. M., Rodriguez, N. M., Pimentel, J. C. M., Martins, G. A., Ribeiro, T. P., Costa, J. B., Santos, S.F., \& Carvalho, F. C. (2007) Valor nutritivo do resíduo da indústria processadora de abacaxi (Ananascomosus L.) em dietas para ovinos. 1. Consumo, digestibilidade parente e 
balanços energético e nitrogenado. Arquivos Brasileiros de Medicina Veterinária e Zootecnia, 59(3), 773-781. https://doi.org/10.1590/S010209352007000300032

Rosenberg, L., Krieger, Y., Silberstein, E., Arnon, O., Sinelnikov, I. A., Bogdanov-Berezovsky, A., \& Singer, A. J. (2012). Selectivity of a bromelain based enzymatic debridement agent: a porcine study. Burns: journal of the International Society for Burn Injuries, 38(7), 1035-1040. https://doi.org/10.1016/j.burns.2012.02.011

Sanches, N. F., \& de Matos, A. P. (2013). Abacaxi: o produtor pergunta, a Embrapa responde. Área de Informação da Sede-Col Criar Plantar ABC 500P/500R Saber (INFOTECA-E). https://mais500p500r.sct.embrapa.br/view/pdfs/90000025-ebook-pdf.pdf

Salgado, J. (2017). Alimentos funcionais. Editora Oficina de Textos.

Sanjairaj, V., Iniyan, S. \& Goic, R. (2012). A review of solar drying technologies. Renewable and Sustainable Energy Reviews. 16. $2652-2670$. 10.1016/j.rser.2012.01.007.

Santini, A. T., Souza, B. S., Oliveira, D. C., Oliveira, M. D., Borges, S. S., \& Cardoso, P. F. (2013). Aproveitamento da casca de abacaxi na confecção de geleia. $5^{a}$ Jornada Científica e Tecnológica e $2^{\circ}$ Simpósio de Pós-Graduação do IFSULDEMINAS. Inconfidentes/MG, 06 a 09 de novembro de 2013.https://jornada.ifsuldeminas.edu.br/index.php/jcinc/jcinc/paper/viewFile/235/146\#: :text=Tanto\%20a\%20casca\%20como\%20o,CONCEI\%C3\%87\%C3 $\% 83 \mathrm{O} \% 3 \mathrm{~B} \% 20 \mathrm{CARVALHO} \% 2 \mathrm{C} \% 202002)$.

Santos, A. R. R., Ciabotti, S., Pereira, J. M. A., Gonçalves, C. A. A., \& Campagnol, P. C. B. (2010). Avaliação da composição centesimal de casca de abacaxi (1-4). III Seminário de Iniciação Científica e Inovação Tecnológica. https://iftm.edu.br/sin/2010/trabalhos/ali_avaliacao_da_composicaoo_centesimal.pdf

Sarzi, B., Durigan, J. F., \& Junior, O. D. (2002). Temperatura e tipo de preparo na conservação de produto minimamente processado de abacaxi 'Pérola'. Revista Brasileira de Fruticultura, 24(2), 376-380. 10.1590/S0100-29452002000200020

Secor, E. R., Jr, Carson, W. F., 4th, Cloutier, M. M., Guernsey, L. A., Schramm, C. M., Wu, C. A., \& Thrall, R. S. (2005). Bromelain exerts anti-inflammatory effects in an ovalbumin-induced murine model of allergic airway disease. Cellular immunology, 237(1), 68-75. https://doi.org/10.1016/j.cellimm.2005.10.002

Silva, R. A. (2008). Caracterização físico-química e purificação da bromelina no Ananas comosus (L.) Merrill (ABACAXI-BROMELIACEAE). Dissertação de Mestrado em Bioquimica e Fisiologia. Universidade Federal de Pernambuco. https://repositorio.ufpe.br/bitstream/123456789/1391/2/RAS.pdf

Silva, I. D. (2013). Obtenção e caracterização de bromelina a partir de diferentes partes do abacaxizeiro Ananas comosus. Dissertação (Mestrado em Recursos Genéticos Vegetais) -Universidade $\quad$ Estadual de $\quad$ Feira $\quad$ de $\quad$ Santana $\quad-\quad$ UEFS. 2013. http://www.rgv.uefs.br/arquivos/File/Downloads/teses_e_dissertacoes/51_idiane_dissertacao_completa_30092013.pdf

Silvestre, M. Carreira, R. Silva, M. Corgosinho, F. Monteiro, M. \& Morais, H. (2012). Effect of pH and Temperature on the Activity of Enzymatic Extracts from Pineapple Peel. Food and Bioprocess Technology - FOOD BIOPROCESS TECHNOL. 5. 10.1007/s11947-011-0616-5.

Siti Rocha, A. M., Zainal, S., Noriham, A., \& Nadzirah, K. Z. (2013). Determination of sugar content in pineapple waste variety N36. International Food Research Journal, $\quad$ v. 20, 2013 http://www.ifrj.upm.edu.my/20\%20(04)\%202013/61\%20IFRJ\%2020\%20(04)\%202013\%20Zainal\%20UiTM\%20(063).pdf

Sobrinho, I. S. B. (2014). Propriedades Nutricionais e Funcionais de resíduos de abacaxi, acerola e cajá oriundos da indústria produtora de polpas. 2014. Dissertação (Mestrado em Ciências Ambientais) - Universidade Estadual do Sudoeste da Bahia - UESB. 2014. http://www2.uesb.br/ppg/ppgca/wpcontent/uploads/2017/11/Disserta\%C3\%A7\%C3\%A3o-FINAL-IVAN-01-04-14.pdf

Sousa, F. C. A., Da Costa Almeida, L. B., \& Silva, R. C. C. (2018). Alimentos funcionais no manejo do Diabetes Melitus tipo 2: uma abordagem bibliográfica. Revista Ciência e Saberes Facema. 3(4), 727-731. https://www.facema.edu.br/ojs/index. php/ReOnFacema/article/view/201

Sousa, A. A. S., \& Moura Fé, L. A. D. M. (2017). Sensibilização de adultos hipertensos sobre a importância do consumo de alimentos funcionais em uma unidade básica de saúde de piripiri-pi. Universidade Federal do Piauí (UFPI). https://ares.unasus.gov.br/acervo/html/ARES/13830/1/ARTIGO.pdf

Tanemura, N., Machii, Y., \& Urushihara, H. (2020). The first survey of gap between the actual labelling and efficacy information of functional substances in food under the regulatory processes in Japan. Journal of Functional Foods. 72. 104047. 10.1016/j.jff.2020.104047.

Teixeira, P. J.B. (2013). Conceitos em Fitoterapia: Uma revisão da literatura. Abacaxi/Bromelina. Universidade Federal de Juiz de Fora. Programa de plantas medicinais e terapias não convencionais. http://www.ufjf.br/proplamed/fitoterapia/2157-2/. Acesso em: nov 2020.

UFPA. O Que São Alimentos Funcionais? Universidade Federal do Pará - Restaurante Universitário. http://ru.ufpa.br/index.php?option=com_content\&view=article\&id=25\&Itemid=10.

Vidal, A. M., Dias, D. O., Martins, E. S. M., Oliveira, R. S., Nascimento, R. M. S., \& Correia, M. das G. da S. (2012). A ingestão de alimentos funcionais e sua contribuição para a diminuição da incidência de doenças. Caderno De Graduação - Ciências Biológicas E Da Saúde - UNIT - SERGIPE, 1(1), 43-52. https://periodicos.set.edu.br/cadernobiologicas/article/view/284

Vieira, E. C. S.., Silva, E. P., Amorim, C. C. M., Sousa, G. M., Becker, F. S., \& Damiani, C. (2017). Aceitabilidade e características físico-quimicas de geleia mista de casca de abacaxi e polpa de pêssego. Científica: Revista de Ciências Agrárias. 45(2). http://www.cientifica.org.br/index.php/cientifica/article/view/988

Viganó, J. (2012). Propriedades termodinâmicas de adsorção de água e cinética de secagem de subprodutos da industrialização de abacaxi (ananás comosus l.) - casca e cilindro central. 88 f. Dissertação (mestrado) - Universidade Estadual Paulista, Instituto de Biociências, Letras e Ciências Exatas, 2012. https://repositorio.unesp.br/handle/11449/90762 